\title{
Power Control Strategy and Performance Evaluation of a Novel Two-pump Hydraulic Control Unit for BEVs
}

\author{
Yanfang Liu ( $\sim$ liuyf@buaa.edu.cn ) \\ Beihang University https://orcid.org/0000-0003-2570-5405 \\ Yanlong Kang \\ Beihang University \\ Wenbo Sun \\ Beihang University \\ Xiangyang $\mathrm{Xu}$ \\ Beihang University
}

Original Article

Keywords: Battery electric vehicles, two-speed transmission, two-pump system, Hardware-in-the-loop simulation

Posted Date: November 4th, 2020

DOl: https://doi.org/10.21203/rs.3.rs-98294/v1

License: (c) (i) This work is licensed under a Creative Commons Attribution 4.0 International License. Read Full License 


\section{RESEARCH}

\section{Power Control Strategy and Performance Evaluation of a Novel Two-pump Hydraulic Control Unit for BEVs}

Yanfang Liu ${ }^{1,2,3^{*}}$, Yanlong Kang ${ }^{1,2}$, Wenbo Sun ${ }^{1,2}$ and Xiangyang $\mathrm{Xu}^{1,2,3}$

${ }^{*}$ Correspondence: liuyf@buaa.edu.cn

${ }^{1}$ School of Transportation Science and Engineering, Beihang

University, Beijing, China Full list of author information is available at the end of the article

\begin{abstract}
A hydraulic control unit system with a mechanical oil pump (MOP) and an electric oil pump (EOP) was newly designed for the lubrication and clutch-to-clutch control of a two-speed dedicated electric transmission for battery electric vehicles (BEVs), in order to solve the high-cost, poor-noise and high-energy-consumption problem exposed in previous single-EOP design with big displacement. The driving motor for BEVs can't idle like the combustion engine when the vehicle stops still, so an EOP with small displacement is required to supply enough fluid to start the vehicle except to a low-cost MOP. Four control algorithms for the two-pump system were developed as well as the main line pressure control strategy, which were confirmed by a Hardware-in-the-Loop (HIL) test bench. The simulated and tested total pump energy consumption in a driving circle WLTC shows that the equal-power control algorithm and the transient on-demand control algorithm can obtain better performance for saving energy consumption. Several oil displacement parameter groups for the MOP and the EOP are discussed, and the results show that proper displacement group for the EOP and the MOP can obtain good balance for the total cost and the performance with the combination of proper two-pump control strategies.
\end{abstract}

Keywords: Battery electric vehicles; two-speed transmission; two-pump system; Hardware-in-the-loop simulation

\section{Introduction}

With the increasingly prominent environmental problem and the shortage of energy, people have higher and higher requirements on the energy economy of automobiles. The battery electric vehicles (BEVs), which are recognized as energy saving and environmental friendly in urban or other special areas, have been developed rapidly in recent years $[1,2]$. Considering the motors' advantages of providing constant torque at low speed while constant power at high speed, fixed ratio reducers are equipped in most mass-produced BEVs in the current automobile market, such as BAIC EU series and BYD e6 of China, Tesla Model S of USA, BMW i3 of Germany and so on. However, simulation results show that the motor can work more efficiently by equipping a two-speed or three-speed automatic transmission with it and so improve the vehicle dynamic and economy significantly [3].

Much research work has been conducted about multi-speed transmissions for BEVs. GKN of Germany designed a two-speed automatic transmission using fixedshaft gear structure and electronic shifting mechanism [4]. IAV of Germany designed 
a power-shift two-speed transmission with a hydraulic module, powered by an integrated electric oil pump [5]. Antonov Automotive Technologies Ltd. of UK designed a three-speed transmission that enables electric vehicles to match the performance of conventional vehicles fitted with internal combustion engines. The transmission adopts a hydraulic system with two pumps, one provides large flow rate with low pressure, the other provides low flow rate with high pressure, to reduce the power requirements [6]. Schaeffler GmbH of Germany designed a two-speed electric drive axle adopted planetary gear design with a motor to achieve shifting. Prof. Song from Tsinghua University designed a two-speed automatic mechanical transmission based on a planetary gear set, with brake band to accomplish gearshift $[7,8]$. Hunan University designed a two-speed automatic transmission with two pairs of spur gears and a set of synchronizer controlled by an electric actuator [9]. A research group instructed by Prof. Chen from Hebei University of Technology designed a two-speed transmission adopted fixed shaft gears, using motors to control shifting actuators and adjusting the speed of traction motor during the shifting process [10]. Yang Tian from University of Technology Sydney proposed a novel two-speed transmission for battery electric vehicles with a shifting system including an one-way-clutch and brake clutches [11]. Our team designed a two-speed automatic transmission with two pairs of spur gears and two identical wet clutches, named as 2DET in the reference [10] as shown in Fig. 1a, and its shifting logic is shown in Fig. 1b. Fixed shaft gears usually have higher efficiency than planetary gears and their ratio are easy to be adjusted without changing size. Although the motor is easy to adjust its rotational speed fast, the shift shock on the vehicle because of the inherent defect of non-powershift mechanism is difficult to be accepted by automobile OEMs and customers. Therefore, power-shift will be expected to be the first choice for A+ and B-class electric vehicles. Convenient power-shift mechanisms universally adopt hydraulic control units (HCUs) to shift gears.

The 2DET has two identical wet clutches without a torque converter, so a HCU is indispensable for engaging or disengaging these two wet clutches. For automatic transmissions (ATs) in traditional combustion vehicles, the mechanical oil pump (MOP) driven by the engine provides enough flow and pressure for the HCU. However, for BEVs, since there is no idle state for the motor when the vehicle is parked, so an electric oil pump (EOP) or some other elements similar to accumulator are required when the vehicle starts or runs at early stage to make up the insufficient flow of MOP. Previously developed HCU for 2DET used only one EOP [12]. Through vehicle test, it can be found that the EOP has high energy consumption because of its large displacement in order to meet all running conditions. Meanwhile, there are few mass-produced EOP available in the current market, and most of their prototypes lack reliability verification. Considering all above information, a new HCU based on a two-pump system is developed to provide sufficient flow and pressure for 2DET and the control algorithms of the two-pump system is discussed here.

In traditional ATs, the constant-displacement mechanical oil pump accounts for $40 \%$ of the total power loss [13], so the oil supply and pressure regulation subsystem of the HCU is critical. In order to achieve higher efficiency, the variable-displacement pump is applied [14]. When the engine speed is too high, the displacement of the MOP will be reduced, which can save more energy. Eduardo G. Ribeiro et at., 
Figure 1: 2DET introduction.

from Dana Pump Products Brasil, said that the use of EOPs allows more freedom to design a lubrication system and the EOP control leads to better efficiency of the system [15]. Eduardo Gubbiotti Ribeiro, from WOP Ind. e Com. de Bombas Ltda, controlled the fluid flow by using the EOP to circulate the cooling fluid under pressure [16]. Yang Liu from Beihang University proposed a flow-based control algorithm of the EOP for a two-pump system in an 8-speed automatic transmission to realized start-stop function [17-19]. Yeonho Kim from Hyundai Kia R\&D Center developed a control algorithm for the electric oil pump (EOP) in hybrid electric vehicles (HEVs) in 2011. They proposed three control algorithms mainly discussed on their collaboration control between the EOP and the MOP by simulation [20]. In 2012, based on a six-speed automatic transmission for HEVs, Kim proposed a power-based control algorithm for an EOP. The proposed control algorithm uses the viscosity factor to indicate the temperature of the AT fluid and controls the EOP based on the required power, leading to a small difference among various EOP qualities [21]. In 2014, Jin Young Hwang from Hyundai Motor developed a two-pump system for AT. They analyzed several HCUs consisting of a two-pump system and adopted a serial-two-pump system. The bench test results showed that the two-pump system can reduce the pump driving power by $40 \%$ to $50 \%$ [13].

Under the condition that the main fluid line pressure is high enough for engaging the clutch and flow is abundant for cooling and lubrication, reducing the output pressure and flow of the oil pump as far as possible can reduce the loss of the HCU and improve the efficiency [22]. In this paper, a HCU for the 2DET adopted a twopump system is designed and corresponding control algorithms for the two pump system is discussed. The rest of the paper is structured as follows: In section 2, a two-pump HCU consisted of an EOP and a MOP is designed. We then proposed four control algorithms and discuss them in terms of reducing the energy loss under the condition of meeting the requirements for each component in the 2DET in section 3. Simulations and HIL bench tests of the four proposed algorithms are carried out in section 4 and section 5. Finally, the displacement combination of the MOP and EOP is optimized in section 6 .

\section{2A new-designed two-pump HCU}

In order to mainly solve the vehicle start problem at zero motor speed and high energy consumption of applying single EOP with high displacement in the A-prototype of 2DET, where an EOP is assembled on the outside housing of 2DET, a MOP is added to be connected with the transmission intermediate shaft in the B-prototype of 2DET. So, there is a new-designed two-pump HCU system developed for the B-prototype 2DET, shown in Fig.1a.

\subsection{Requirement Analysis of the new-designed two-pump HCU}

Considering the structural layout of 2DET, the HCU should have the following functions: 
Figure 2: The schematic diagram of the new-designed HCU for 2DET and its physical picture

- To realize the fundamental function of shifting gears smoothly, the HCU can control two wet clutches precisely and independently;

- To realize the fundamental function of shifting gears smoothly, the HCU can control two wet clutches precisely and independently;

- The HCU should realize the $1^{\text {st }}$ gear when the car stops still since the motor does not have idle stage as the engine;

- The HCU should realize the $1^{s t}$ gear when the car reverses;

- The two-pump HCU should have good controllability and high efficiency.

\subsection{Structural Design of the two-pump HCU}

Fig. 2a shows the schematic diagram of our new designed two-pump HCU. Two pumps work parallelly to supply the automatic transmission fluid (ATF) to the main line through two separate check valves. Three large-flow solenoid valves S0, DAV_1, DAV_2 are designed to connect to the main line parallelly. The solenoid valve S0, connected with the feedback chamber of the high-pressure control valve (HP_CV), is designed to adjust the mail line pressure and the cooling and lubrication flow into the gearbox. The solenoid valves DAV_1 and DAV_2 are designed to control the clutches $\mathrm{C} 1$ and $\mathrm{C} 2$, respectively [17].

The MOP is driven by the transmission intermediate shaft of $2 \mathrm{DET}$ and the EOP is driven by a motor. Check valves are installed behind the output of pumps to prevent the reverse flow of ATF. The EOP is composed of an internal gear pump, a motor and a controller, so the efficiency of the EOP is determined together by all parts [23], which must be considered when designing the EOP and the MOP. Additionally, the performance of the HCU is independent of the characteristics of selected ATF. Fig. 3 shows the viscosity-temperature characteristics of the ATF used in 2DET.

Here, the EOP is designed to compensate the flow of the MOP. Thus, the EOP mainly works when the car runs at low speed or stops still. The EOP will stop working for saving energy when the velocity of the car is high enough, and meanwhile the MOP only needs to meet the requirement of $\mathrm{HCU}$ when the car runs at high speed. Therefore, the displacements of the MOP and the EOP must be optimized to satisfy these points, which is discussed in later sections.

Two extreme conditions should be considered to design suitable EOP and MOP [20]:

1 At extremely cold temperature, high viscosity will lead to large shear force, so the motor power of the EOP must be high enough to drive the gear pump;

2 At extremely high temperature, low viscosity will increase the leakage, so the EOP and MOP must meet the total flow requirement of $2 \mathrm{DET}$.

\section{Control strategy}

For the above new-designed two-pump HCU, there are two main control physical variables: one is the rotational speed of the EOP, and the other is the main line pressure. 
Figure 3: Viscosity of ATF.

Figure 4: Macro-control strategy for the EOP.

\subsection{Flow control strategy of two pumps}

The battery supply $12 \mathrm{~V}$ voltage to drive the motor of the EOP and the rotation speed of EOP is controlled by the transmission control unit (TCU) of 2DET. Since only the EOP can supply ATF for the HCU when backing the car, the EOP's control algorithm is considered under forward condition rather than reverse condition.

Fig. 4 shows the macro-control strategy for the EOP in the whole forward speed phase of the car. Firstly, when the vehicle moves forward slowly, the EOP will work to supplement the flow of the MOP. When the vehicle reaches a certain speed at which the MOP can provide enough flow, the EOP will stop working. In order to prevent the EOP from switching between on and off frequently, the vehicle speed of stopping the EOP is controlled to be slightly higher than the one of starting the EOP. As for the detailed working state, there are four micro-control algorithms for the EOP, as shown in Fig. 5, i.e. one-speed control, two-speed control, equal-power control and transient on-demand control [20].

\subsubsection{One-speed control algorithm for the EOP}

In this control algorithm, the speed for stopping the EOP is prescribed according to whether the MOP meets the flow and pressure requirements of 2DET. The corresponding vehicle speed for stopping the EOP can be calculated from the following equation:

$$
\begin{gathered}
Q_{M O P}=Q_{\text {target }} \\
N_{M O P}=\frac{Q_{M O P}}{\eta D_{M O P}} \\
v=2 \pi \cdot R_{\text {tire }} \cdot i_{0} \cdot N_{M O P}
\end{gathered}
$$

where $Q_{M O P}$ is the flow rate of the MOP, $\eta$ is the lowest efficiency of the MOP, $D_{M O P}$ is the displacement of the MOP; $N_{M O P}$ is the rotation speed of the MOP, $Q_{\text {target }}$ is the target flow rate; $v$ is the vehicle speed, $R_{\text {tire }}$ is the radius of the tire, $i_{0}$ is the ratio of the main reducer since the MOP is installed on the middle shaft. The calculated result is the vehicle speed control parameter for stopping the EOP. Generally, the vehicle speed control parameter for starting the EOP is defined a little higher, here $5 \mathrm{~km} / \mathrm{h}$ is set. This control algorithm is easy to execute. However, the total supply flow from two pumps is superfluous, leading to a waste of energy.

\subsubsection{Two-speed control algorithm}

The working state is divided into three phases according to the vehicle speed in this control algorithm, shown in Fig. 5b. When the car stops still, the EOP works with a low speed to meet the basic requirements of the HCU, i.e. the LSP phase. 
Figure 5: Four micro-control algorithms for the EOP.

Figure 6: The calculated working map of the EOP.

Then the car starts to move forward, the EOP quickly reaches to a high speed, providing required flow to ensure the driving performance of the vehicle with short response time, i.e. the HSP phase. Once reaching a certain vehicle speed at which the MOP supplies more ATF, the EOP is then controlled to reduce its rotational speed to a medium speed, i.e. MSP phase. Finally, once exceeding the EOP-off control point, the EOP will be switched off just like the one-speed control algorithm. This control algorithm can reduce the energy consumption because the EOP speed has a correlation with the vehicle speed. However, detailed work needs to be done to find more optimal stage-change speed.

\subsubsection{Equal-power control algorithm}

The first two phases in this control algorithm are the same as those of the twospeed control algorithm. However, it comes to an equal-power speed control phase rather than a MSP phase after the vehicle reaches a certain speed when the MOP still cannot satisfy the flow requirement. The rotational speed of EOP changes dynamically with the vehicle speed, under the conditions that the sum of the flow provided by the EOP and MOP equals to the target value, that is:

$$
Q_{M O P}+Q_{E O P}=Q_{\text {target }} .
$$

Therefore, there are mainly four stages in equal-power control, the rotational speed of EOP can be determined by the following formula:

$$
N_{E O P}=\left\{\begin{array}{cc}
Q_{\text {min req }} / D_{E O P} & v=0 \\
Q_{\text {target }} / D_{E O P} & 0<v \leq v_{1} \\
\left(Q_{\text {target }}-N_{M O P} \cdot D_{M O P} \cdot \eta\right) / D_{E O P} & v_{1}<v \leq v_{2} \\
0 & v>v_{2}
\end{array}\right.
$$

where $N_{E O P}$ is the rotational speed of EOP; $N_{M O P}$ is the rotational speed of MOP relative to the vehicle speed $v ; Q_{\text {min req }}$ is the flow requirement when the car stops still; $Q_{\text {target }}$ is the target flow requirement of the transmission defined usually as the average flow from an engineering perspective; $D_{E O P}$ and $D_{M O P}$ are the displacements of the EOP and the MOP, respectively; $v_{1}$ and $v_{2}$ are first and second speed points, $v_{2}$ changes according to different working conditions, such as different demand pressure, fluid temperature, etc. This control strategy is energysaving because of the equal-power control stage. Based on the characteristics of the EOP and the MOP, the calculated working map for the EOP is listed in Fig. 6, in which the EOP speed varies with the vehicle speed and acceleration pedal, here initially $D_{E O P}$ is set to be $4.1 \mathrm{cc} / \mathrm{rev}$ and is set to be $4.8 \mathrm{cc} / \mathrm{rev}$. 
Figure 7: Calculated flow requirement of 2DET in a WLTC driving cycle.

Figure 8: Shift line.

\subsubsection{Transient on-demand control algorithm}

For the above three control algorithms, the flow requirements are calculated off-line. However, when it comes to a specific transmission structure, transient requirements to the HCU can be calculated on-line. Actually, the flow requirement to the HCU is not only decided by the vehicle speed, but also by other factors, such as the vehicle acceleration and shifting algorithm. The top red line in Fig. 5(d) is the required ATF flow which may go down and also rise up when the vehicle runs faster. In this way, the transient on-demand control algorithm can reduce further energy consumption.

Taken the driving circle WLTC as an example, the transient flow requirement for the $2 \mathrm{DET}$ can be calculated in real-time according to the vehicle driving condition, see the red line in Fig. 7. The MOP's rotational speed changes with the vehicle speed because of their mechanical connection. Then the EOP is controlled dynamically to supplement the MOP. By using this control algorithm, the two-pump system can provide the required flow based on the real driving condition, which depends on the accuracy of the flow model.

\subsection{Main line pressure control strategy of the $\mathrm{HCU}$}

The pressure for clutches to transfer the required torque can be calculated by:

$$
P_{R}=\frac{T}{\mu \cdot N \cdot A_{P} \cdot r_{M}}+P_{S}
$$

where $P_{R}$ is the pressure demand of the clutch, $T$ is the transferred torque, $\mu$ is the friction coefficient of clutch friction plates, $N$ is the number of friction surfaces, $A_{P}$ is the clutch piston area, $r_{M}$ is the mean radius of the friction plate, $P_{S}$ is the equivalent pressure to overcome the return spring. Taking leakage and pressure drop of the system into consideration, the maximum main line pressure should be slightly higher than $P_{R}$, here 12 bar is set for $2 \mathrm{DET}$.

In fact, BEVs are not always running at full load. To reduce energy consumptions, it is necessary to reduce the main line pressure as far as possible under the condition of satisfying the driving condition of the vehicle [20]. Based on the shift line shown in Fig. 8, the motor output power and the clutch pressure demand for 2DET in the driving cycle is calculated and listed in Fig. 9. The maximum output torque of the motor is about $150 \mathrm{Nm}$ in the driving circle WLTC, far below the maximum motor torque $360 \mathrm{Nm}$. Thus, the required pressure line is always lower than 6 bar. Considering leakages and pressure losses, an additional 12 bar should be added to the required pressure and thus get a main-line pressure control target.

\section{Modeling and simulation}

To verify the performance of these control algorithms mentioned above, the simulation model of the $\mathrm{HCU}$ was built using a multi-domain dynamic modeling and 
Figure 9: Torque and Clutch pressure demand of 2DET in the WLTC cycle.

Figure 10: Simulation model for the new-designed two-pump HCU for 2DET.

simulation software, ITI-SimulationX, as shown in Fig. 10. The displacement of the EOP is set to be $4.1 \mathrm{cc} / \mathrm{rev}$ and the displacement of the MOP is set to be $4.8 \mathrm{cc} / \mathrm{rev}$ initially, and the optimization of the MOP selection will be done in the next section. Here, the ATF temperature is supposed to be $60^{\circ} \mathrm{C}$.

\subsection{Simulation of the two-pump control strategies}

According to the vehicle data of the driving circle WLTC and the transmission ratio from the input shaft to the intermediate shaft, the rotational speed of the MOP can be calculated. According to the transferred torque, the maximum main line pressure was calculated to be 12bar. Firstly, the main line pressure is controlled to be constant at 12 bar just like A-prototype of $2 \mathrm{DET}$ by controlling the current of the solenoid valve S0 to be a certain constant value. Fig. 11 shows the calculated total pump energy consumption of the proposed four algorithms for the driving circle WLTC. Although the one-speed control strategy is simple, there is obviously a large flow waste due to the constant EOP working speed. The total energy consumption with the one-speed control method is $563 \mathrm{~kJ}$. The total energy consumption can be reduced by approximately $11.3 \%$ to $500 \mathrm{~kJ}$ if the two-speed control method is implemented. The equal-power control method would have a better performance, whose total energy consumption is $479 \mathrm{~kJ}$, about further $4 \%$ off than the two-speed control method. The transient on-demand control method has the best performance whose total energy consumption is reduced to 390kJ. Once the EOP has been switched off, the later energy consumption will only depend on the MOP. So the rising slopes of the energy consumption are identical just in the high vehicle speed phase from the 1500 s to 1770 s for four control methods. Fig. 12 lists the simulated pressure results, which shows that the main line pressure is controlled at 12 bar in order to make sure the clutches can transmit the maximum motor torque. There are several shifting processes during the whole 1800s driving circle.

\subsection{Simulation of the transient main line pressure control strategy}

Fig.9 shows that the required clutch pressure is much below 12bar. Therefore, more energy can be saved by adjusting the main line pressure according to the real required clutch pressure in real time. For the new-designed HCU for 2DET, the relationship between the current of the solenoid valve $\mathrm{S} 0$ with the main line pressure

Table 1: Tested results with the equal-power control.

\begin{tabular}{|c|c|c|c|c|c|c|c|c|c|c|c|c|c|}
\hline \multirow[b]{2}{*}{$\operatorname{EOP}(\mathrm{cc} / \mathrm{rev})$} & \multicolumn{13}{|c|}{$\operatorname{MOP}(\mathrm{cc} / \mathrm{rev})$} \\
\hline & 2 & 2.5 & 3 & 3.5 & 4 & 4.5 & 5 & 5.5 & 6 & 6.5 & 7 & 7.5 & 8 \\
\hline 3 & 177 & 179 & 185 & 194 & 207 & 222 & 241 & 263 & 289 & 316 & 347 & 381 & 418 \\
\hline 4 & 177 & 179 & 185 & 194 & 207 & 222 & 241 & 263 & 289 & 316 & 347 & 381 & 418 \\
\hline 5 & 177 & 179 & 185 & 194 & 207 & 222 & 241 & 263 & 289 & 316 & 347 & 381 & 418 \\
\hline
\end{tabular}


Figure 11: Simulated pump energy consumptions.

Figure 12: Simulated main line pressure and clutch pressure.

can be calculated and shown in Fig. 13. Furtherly, the required control current for the solenoid valve S0 can be calculated for the driving circle WLTC.

By controlling the main line pressure in real time without changing other parameters, the total energy consumption results can be simulated again, which are shown in Fig. 14. It is obvious that the transient on-demand control can get the best economic performance, whose total energy consumption is $189 \mathrm{~kJ}$. So the main line pressure control strategy also reduces the pump load, and the controlling result of the main line pressure is shown in Fig. 15, which is mostly near 5bar in most cases while not the maximum.

\subsection{Simulation of the influence of the temperature}

In order to verify the influence of the temperature on the control strategy, some simulations are selected to be conducted under different temperature for the equalpower control strategy and the transient on-demand control strategy, and their simulation results are shown in Fig. 16.

The results show that the temperature does influence the pump total energy consumption for each control algorithm and so must be considered when design the HCU system. There is one point to be noted that the efficiency of the pump is not considered here detailly. Generally, the pumps, either the EOP or the MOP, have poor flow performance at low temperature. So the two-pump system should not take the total energy consumption as the most important evaluation index but the flow supply. Furthermore, the influence of the temperature becomes weak once the temperature rises higher than $60^{\circ} \mathrm{C}$. In order to make the control algorithm simple, two sets of control parameters are usually designed. The above control algorithms are for normal temperatures. Some compensation algorithms are designed for special temperature based on the above control algorithms, which is not discussed in detail here because they are beyond the object of this paper.

\section{Test and validation}

The dSPACE runs the vehicle model, the driver model, the motor model and the transmission model for the driving cycle WLTC, which are downloaded into the dSPACE box in advance. The TCU runs the two-pump control algorithms based on

Table 2: Tested results with the transient on-demand control.

\begin{tabular}{lccccccccccccc}
\hline & \multicolumn{1}{l}{ MOP(cc/rev) } & 10.5 & 10 \\
\cline { 2 - 12 } EOP $(\mathrm{cc} / \mathrm{rev})$ & 2 & 2.5 & 3 & 3.5 & 4 & 4.5 & 5 & 5.5 & 6 & 6.5 & 7 & 7.5 & 8 \\
\hline 3 & 78 & 93 & 111 & 130 & 151 & 174 & 199 & 226 & 255 & 286 & 320 & 356 & 396 \\
4 & 78 & 93 & 111 & 130 & 151 & 174 & 199 & 226 & 255 & 286 & 320 & 356 & 396 \\
5 & 78 & 93 & 111 & 130 & 151 & 174 & 199 & 226 & 255 & 286 & 320 & 356 & 396 \\
\hline
\end{tabular}


Figure 13: Relationship of main line pressure with current of solenoid valve S0.

Figure 14: Pump energy consumption with transient main line pressure control.

the control software of 2DET, which are also downloaded into the TCU in advance. TCU outputs the control command based on the vehicle state information transited from the dSPACE. Fig. 18 lists the small deviation between the tested vehicle speed with the driving cycle WLTC, which proves the effectiveness of the HiL test system. The tested vehicle speed maintains good consistency with the target speed, and thus the HiL test model is used to test the control algorithms.

In order to verify the proposed four control algorithms, a Hardware-in-Loop (HiL) physical system is built based on the dSPACE control box, a TCU of 2DET and the control host, which is shown in Fig. 17. The dSPACE communicates with the TCU through their I/O interfaces in real time. The host can calibrate the parameters during the process of testing as well as measure and record the test results.

Fig. 19 lists the EOP speed change example for different control algorithms from 1010 s to $1045 \mathrm{~s}$. The EOP rapidly reached $2500 \mathrm{rpm}$ in the two-speed control and the equal-power control. With the increasing of the vehicle speed, the EOP runs into the MSP phase in the two-speed control and runs into the equal power phase in the equal-power control. However, the EOP keeps working at 2500rpm until the vehicle speed drives the MOP to provide enough flow, at that time the EOP will stop to work in the two-speed control and the equal-power control. In the transient on-demand control, the EOP speed is relatively small comparing to other controls, which is the real reason for the significant energy-saving effect. Fig. 20 lists the tested pump energy consumption of four control algorithms in the driving cycle WLTC. Similar to Fig. 14, the transient on-demand control has the best economic performance, which is about $185 \mathrm{~kJ}$ for one driving cycle, in which $100 \mathrm{~kJ}$ is saved comparing with the one-speed control.

\section{Optimal pump oil displacement parameter group}

$\mathrm{s}$ discussed in Fig. 1, the MOP is mechanically connected to the intermediate shaft of 2DET, so the flow of ATF supplied by the MOP depends on the vehicle speed and the difference between the required and the supply of MOP is the required flow for the EOP. The EOP is controlled independently by its motor. So the displacement of the MOP is more important design parameter for energy saving than the one of the EOP.

Several design parameter groups were designed and tested by changing the MOP's displacement from $2 \mathrm{cc} / \mathrm{rev}$ to $8 \mathrm{cc} / \mathrm{rev}$ and the EOP's displacement from $3 \mathrm{cc} / \mathrm{rev}$ to

Table 3: Energy saving results with different displacement of MOP.

\begin{tabular}{lccccccccccccc}
\hline MOP(cc/rev) & 2 & 2.5 & 3 & 3.5 & 4 & 4.5 & 5 & 5.5 & 6 & 6.5 & 7 & 7.5 & 8 \\
\hline $\begin{array}{c}\text { Energy } \\
\text { save(\%) }\end{array}$ & 55.5 & 47.7 & 40.0 & 33.0 & 26.9 & 21.7 & 17.6 & 14.3 & 11.7 & 9.6 & 7.9 & 6.5 & 5.3 \\
\hline
\end{tabular}


Figure 15: Simulated main line pressure in the driving circle WLTC.

Figure 16: Pump energy consumption under different temperature.

$5 \mathrm{cc} / \mathrm{rev}$. Table 1 and Table 2 show the tested results with the equal-power control and the transient on-demand control, respectively. The results show that the total pump energy consumption for a driving circle WLTC is remotely connected with the EOP's displacement but largely connected with the MOP's displacement, and the minimum total energy consumption is obtained when the displacement of MOP is set to be $2 \mathrm{cc} / \mathrm{rev}$. Larger displacement of the MOP leads to more consumed energy, since the MOP will provide superfluous flow when the vehicle speed is high. Table 3 lists the maximum energy saving results for different MOP's displacement. Small displacement of the MOP can enlarge the working scope of the EOP so get better energy saving results. Thus, if the transient on-demand control is used in the TCU, the displacement of the MOP should be smaller than $5 \mathrm{cc} / \mathrm{rev}$ in order to save more than $20 \%$ energy. However, this does not mean that the displacement of MOP should be as small as possible since a super small displacement MOP will not only have a poor efficiency performance but also be expensive. So the cost of the whole HCU must be balanced for the mass production.

\section{Conclusions}

A two-pump HCU is new designed for the B-prototype of a two-speed dedicated electric transmission (2DET) for BEVs from the perspective of cost and performance, while the single-EOP design with big displacement is abandoned because of its high cost and poor NVH performance of the EOP. The new-designed two-pump HCU system can meet the requirement for shifting gears and lubrication during the process of driving the vehicle forward or backward and stopping still.

Several control algorithms have been developed for the new-designed two-pump HCU system, whose effectiveness is validated by the HiL test. The transient ondemand control algorithm can reduce the total pump energy consumption in a driving circle WLTC significantly from $562 \mathrm{~kJ}$ to $390 \mathrm{~kJ}$. Additionally, the total pump energy consumption can be reduced further to $189 \mathrm{~kJ}$ with the transient on-demand control by adjusting the mail line pressure.

The displacement combination of the MOP and EOP determines the final performance and cost of the new-designed two-pump HCU system. The tested results show that the total pump energy consumption for a driving circle WLTC is remotely connected with the displacement of EOP but largely connected with the MOP's displacement, and so an optimal displacement group for the MOP and EOP can be designed for the final design.

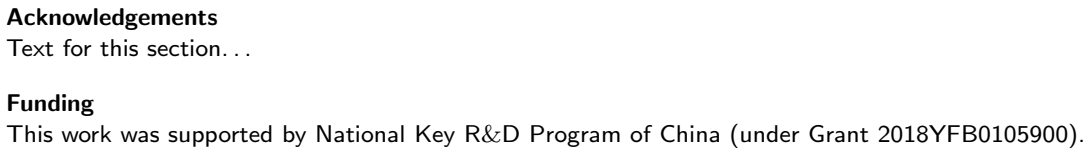


Figure 17: Hardware-in-the-Loop.

Figure 18: WLTC driving cycle and simulation speed.

Availability of data and materials

Competing interests

The authors declare that they have no competing interests.

Authors' contributions

Yanfang Liu has designed the MOP and EOP and written this paper. Yanlong Kang and Wenbo Sun have conducted

Hardware-in-loop experiments and simulations to verify the proposed methods. Xiangyang Xu has revised this paper.

Authors' information

Yanfang Liu is an Associate Professor in the Department of Automobile Engineering at Beihang University. She received her B.Sc. in Mechanical Design and Manufacturing from Qilu University of Technology in 2000. She completed her Ph.D. Degree in Aerospace Science and Technology in 2006. She held a postdoctoral research position at the Department of Automobile Engineering in Beihang University from Jan. 2006 until Nov. 2007 and then a Teacher Staff at the Department of Automobile Engineering in the School of Transportation Science and Engineering of Beihang University till now. She was a visiting scholar in Mechanical Engineering at Chemnitz University of Technology in German in 2008 and in Mechanical and Material Engineering at Wright State University in the United States from Aug. 2014 to Aug. 2015, respectively. Liu conducts research in modeling and control for applications in advanced electromechanical coupling transmission system in automobile, with a specialization in Electro-hydraulic Clutch Control. Liu is the recipient of a First Prize of China Automotive Industry Science and Technology Progress Award ranked 5th personally in 2015, Second Prize of Beijing Graduate Teaching Achievements ranked 2nd personally in 2017.

Wenbo Sun received his B.Sc. from Beihang University in 2017 and M.Sc. from Beihang University in Jan. 2020, both in Mechanical Engineering. He worked on developing hydraulic control units for a two-speed dedicated electric transmission during his master program. His research interests include control amd mechatronics systems design. Xiangyang Xu received the B.S. and M.S. degrees in vehicle engineering from the Beijing Institute of Technology (BIT), Beijing, China, in 1987 and 1990 and the Ph.D. degree in mechanical and electronic engineering from the Harbin Institute of Technology, Harbin, China, in 1999. He is currently a Professor and the Director of the Beijing Key Laboratory for High-efficient Powertrain and System Control of New Energy Resource Vehicle, Beihang University (BUAA). He has developed the world's first front-drive 8-speed automatic transmission (8AT) and its series of products. In 2016, he won the first prize of National Science and Technology Progress Award (the first finisher).

\section{Author details}

${ }^{1}$ School of Transportation Science and Engineering, Beihang University, Beijing, China. ${ }^{2}$ Beijing Key Laboratory for High-efficient Power Transmission and System Control of New Energy Resource Vehicle, Beihang University, Beijing, China. ${ }^{3}$ Ningbo Institute of Technology (NIT), Beihang University, Ningbo, China.

\section{References}

1. Guang Wu, X.W., Dong, Z.: Powertrain architectures of electrified vehicles: Review, classification and comparison. Journal of the Franklin Institute 352(2), 425-448 (2015)

2. Zhang, H., Wang, J.: Active steering actuator fault detection for an automatically-steered electric ground vehicle. IEEE Transactions on Vehicular Technology 66(5), 3685-3702 (2017)

3. Zhang Hui, G.Z., Wang, J.: $\mathrm{H} \infty$ observer design for Ipv systems with uncertain measurements on scheduling variables application to an electric ground vehicle. IEEE/ASME Transactions on Mechatronics 21(3), 1659-1670 (2016)

4. Theodor, G., Christian, G.: Transmission technology for hybrid and electric vehicle. In: International Mobility Conference (2012)

5. Erik Schneider, B.C. Frank Fickel, Liebold, J.: Highly integrative and flexible electric drive unit for electric vehicles. Atz Worldwide Emagazine 113(5), 10-15 (2011)

6. Simon, Roberts: Multispeed transmission for electric vehicles. Atz Worldwide 114(1), 8-11 (2012)

7. TruongSinh Nguyena, S.F.H.S.Y.T. Jian Son, Li, F.: Simulation and experimental demonstration of a seamless two-speed automatic mechanical transmission for electric vehicles. Qinghua Daxue Xuebao/Journal of Tsinghua University 57(010), 1106-1113 (2017)

8. Shengnan Fang, H.S.Y.T.F.L. Jian Song, Nguyena, T.: Design and control of a novel two-speed uninterrupted mechanical transmission for electric vehicles. Mechanical Systems and Signal Processing 75(1), 473-493 (2016)

9. Wei Huang, Y.W., Feng, K.: Study on performance of the pure electric vehicle use two-speed transmission. In: World Battery, Hybrid and Fuel Cell Electric Vehicle Symposium and Exhibition (2010)

10. Zhuoqiang Li, Y.C., Li, R.: Parameter matching and optimization of two gear transmission for electric vehicle. utomobile Applied Technology 19(1), 5-8 (2018)

11. Yang Tian, W.M.d.S.Z.N.Z. Haitao Yang, Walker, P.D.: Optimal coordinating gearshift control of a two-speed transmission for battery electric vehicles. Mechanical Systems and Signal Processing 136(1), 106521 (2020) 
Figure 19: Different control algorithms for the EOP.

Figure 20: Energy consumption with HIL test results.

12. Xiangyang Xu, T.C.Y.L. Wenbo Sun, Han, X.: Design of a hydraulic control unit for a two-speed dedicated electric vehicle transmission. Automotive Innovation 1(4), 300-310 (2018)

13. Xiangyang $\mathrm{Xu}$, T.C.Y.L. Wenbo Sun, Han, X.: Design of a hydraulic control unit for a two-speed dedicated electric vehicle transmission. Automotive Innovation 1(4), 300-310 (2018)

14. David Staley, B.P., Gilgenbach, K.: Adaptation of a variable displacement vane pump to engine lube oil applications. In: Sae World Congress and Exhibition (2007)

15. Eduardo G. Ribeiro, W.B.M., Filho, A.P.A.: Application of electric oil pumps on automotive systems. In: SAE Brasil 2005 Congress and Exhibit (2005)

16. Eduardo Gubbiotti Ribeiro, A.P.D.A.F., Meira, J.L.D.C.: Electric water pump for engine cooling. In: SAE Brasil 2007 Congress and Exhibit (2007)

17. Yanfang Liu, P.D. Shuhan Wang, Xu, X.: Dynamic analysis and control of an automatic transmission for start stop function and efficiency improvement. Mathematical Problems in Engineering 2015(1), 1-13 (2015)

18. Yanfang Liu, P.D. Shuhan Wang, $\mathrm{Xu}, \mathrm{X}$.: Dynamic analysis and control of an automatic transmission for start-stop function and efficiency improvement. Mathematical Problems in Engineering 2015(1), 1-13 (2015)

19. Yanfang Liu, Y.L. Peng Dong, $\mathrm{Xu}, \mathrm{X}$.: Design and application of electric oil pump in automatic transmission for efficiency improvement and start-stop function. Journal of Central South University 23(3), 570-580 (2016)

20. Yeonho Kim, C.J.Y.K.M.S.J.K. Jaesang Lee, Kim, H.: Development and control of an electric oil pump for automatic transmission-based hybrid electric vehicle. IEEE Transactions on Vehicular Technology 60(5), 1981-1990 (2011)

21. Son M, O.J., Y, K.: Power-based control of an electric oil pump for an automatic-transmission-based hybrid electric vehicle. In: Proceedings of the Institution of Mechanical Engineers Part D Journalof Automobile Engineeringt (2012)

22. Yeonho Kim, C.J.Y.K.M.S.J.K. Jaesang Lee, Kim, H.: Development and control of an electric oil pump for automatic transmission-based hybrid electric vehicle. IEEE Transactions on Vehicular Technology 60(5), 1981-1990 (2011)

23. Eiji Miyachi, M.I., Mizumoto, K.: Development of electric oil pump 1 (2006) 


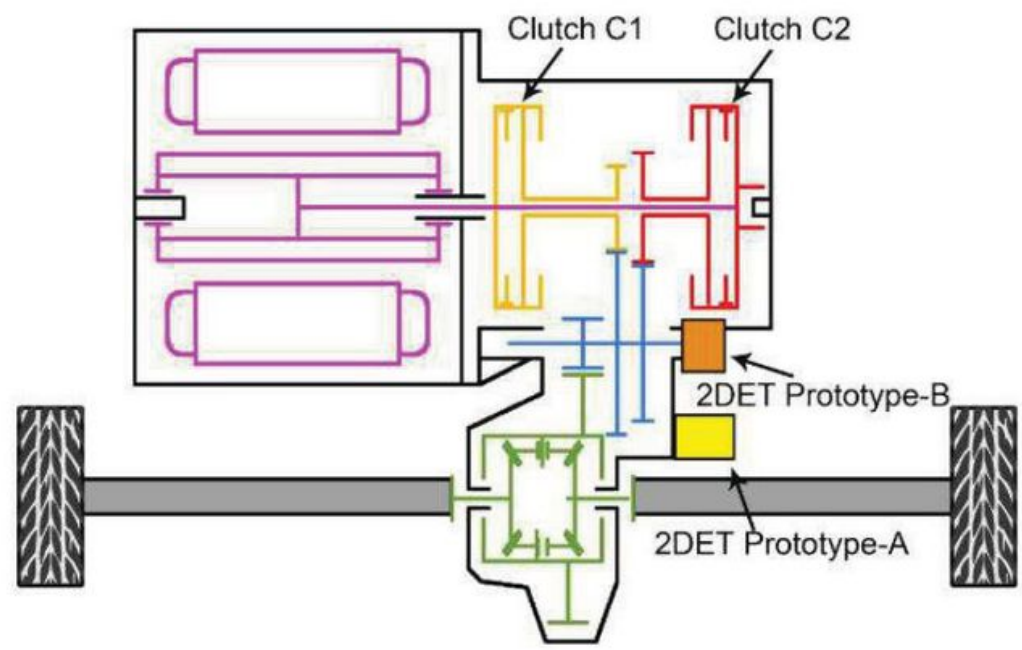

(a) Powertrain.

\begin{tabular}{|c|c|c|}
\hline Gear & \multicolumn{2}{|c|}{ Shifting elements } \\
& $\mathrm{C} 1$ & $\mathrm{C} 2$ \\
\hline $\mathrm{R}$ & $\bullet$ & \\
\hline $\mathrm{N}$ & & \\
\hline $\mathrm{D} 1$ & $\bullet$ & \\
\hline $\mathrm{D} 2$ & & \\
\hline
\end{tabular}

(b) Shift logic.

Figure 1

2DET introduction.

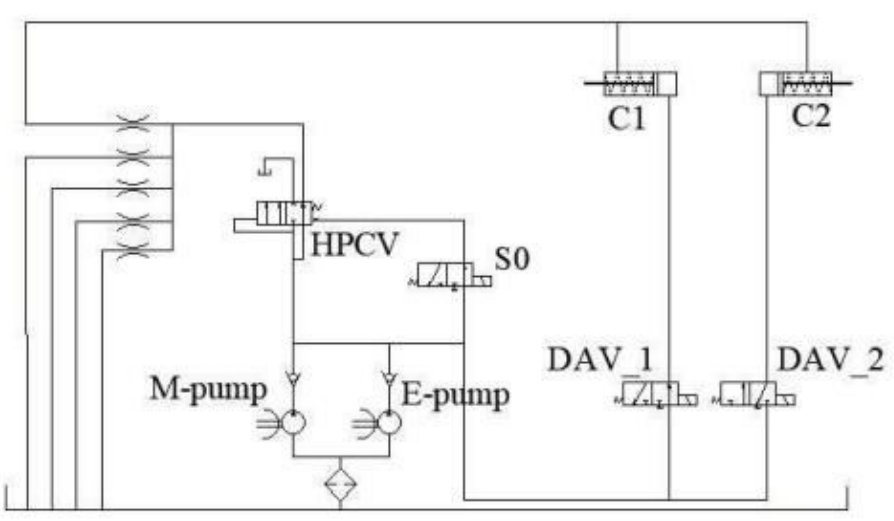

(a) The schematic diagram
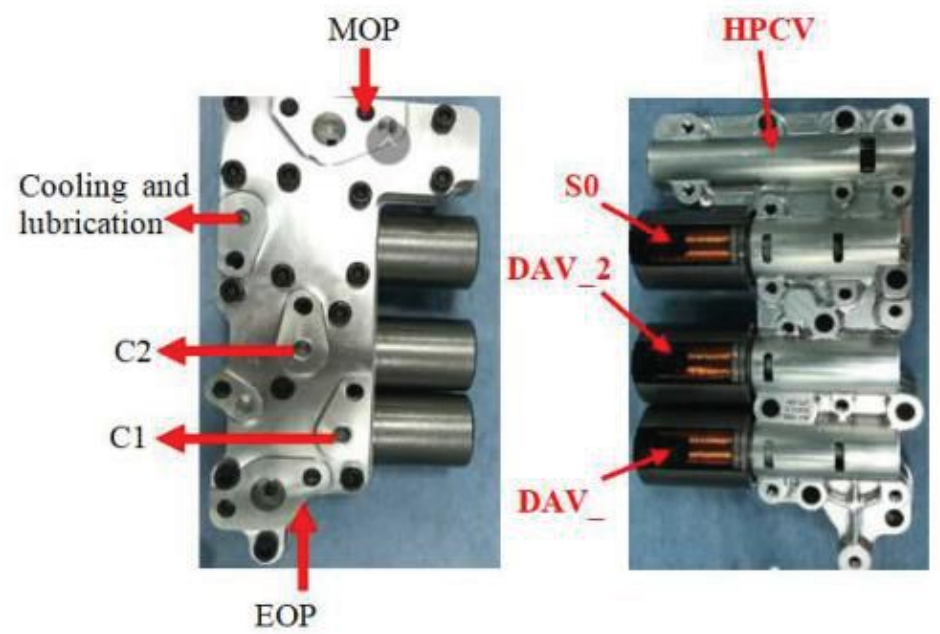

(b) Prototype

Figure 2

The schematic diagram of the new-designed HCU for 2DET and its phys- ical picture 


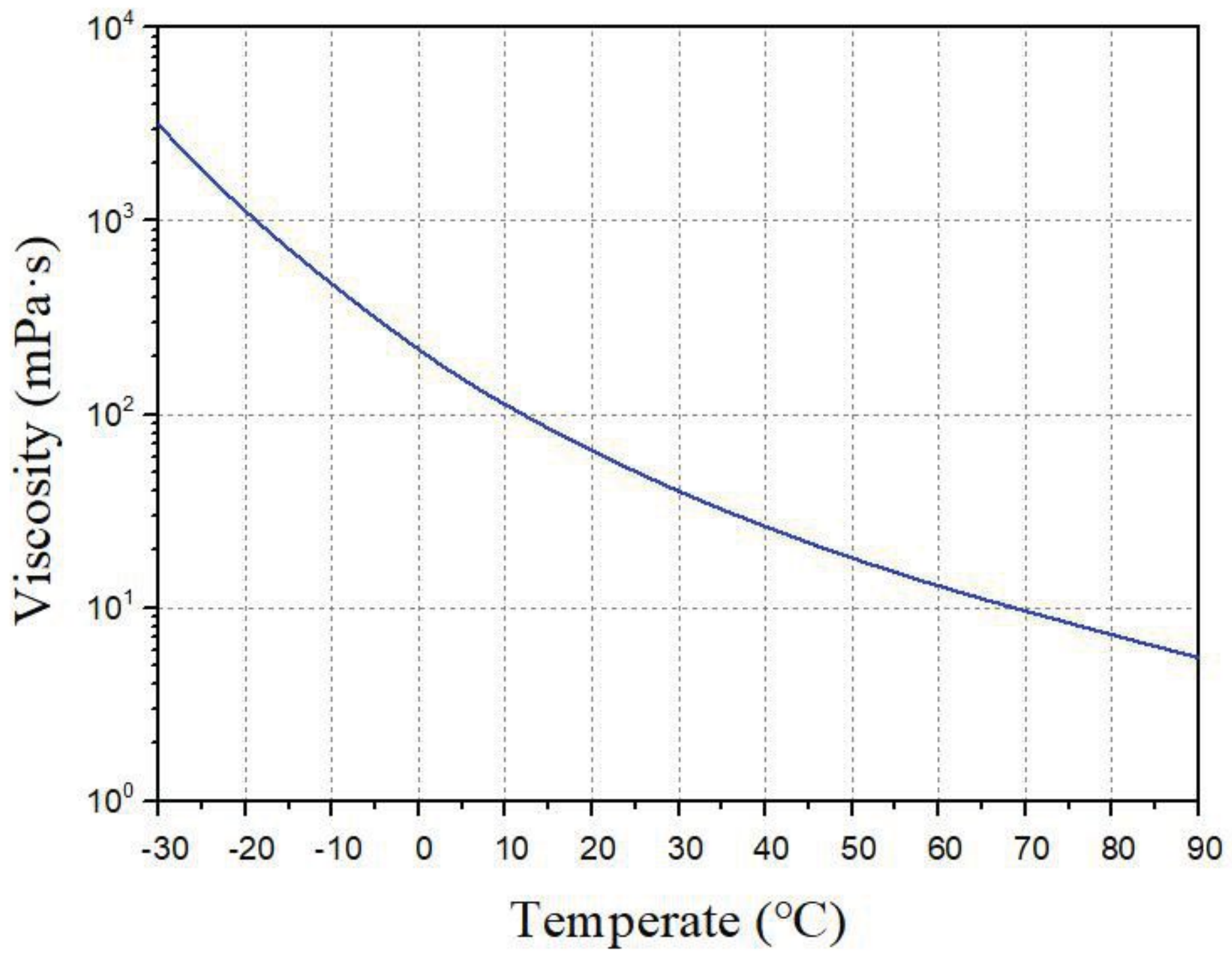

Figure 3

Viscosity of ATF. 


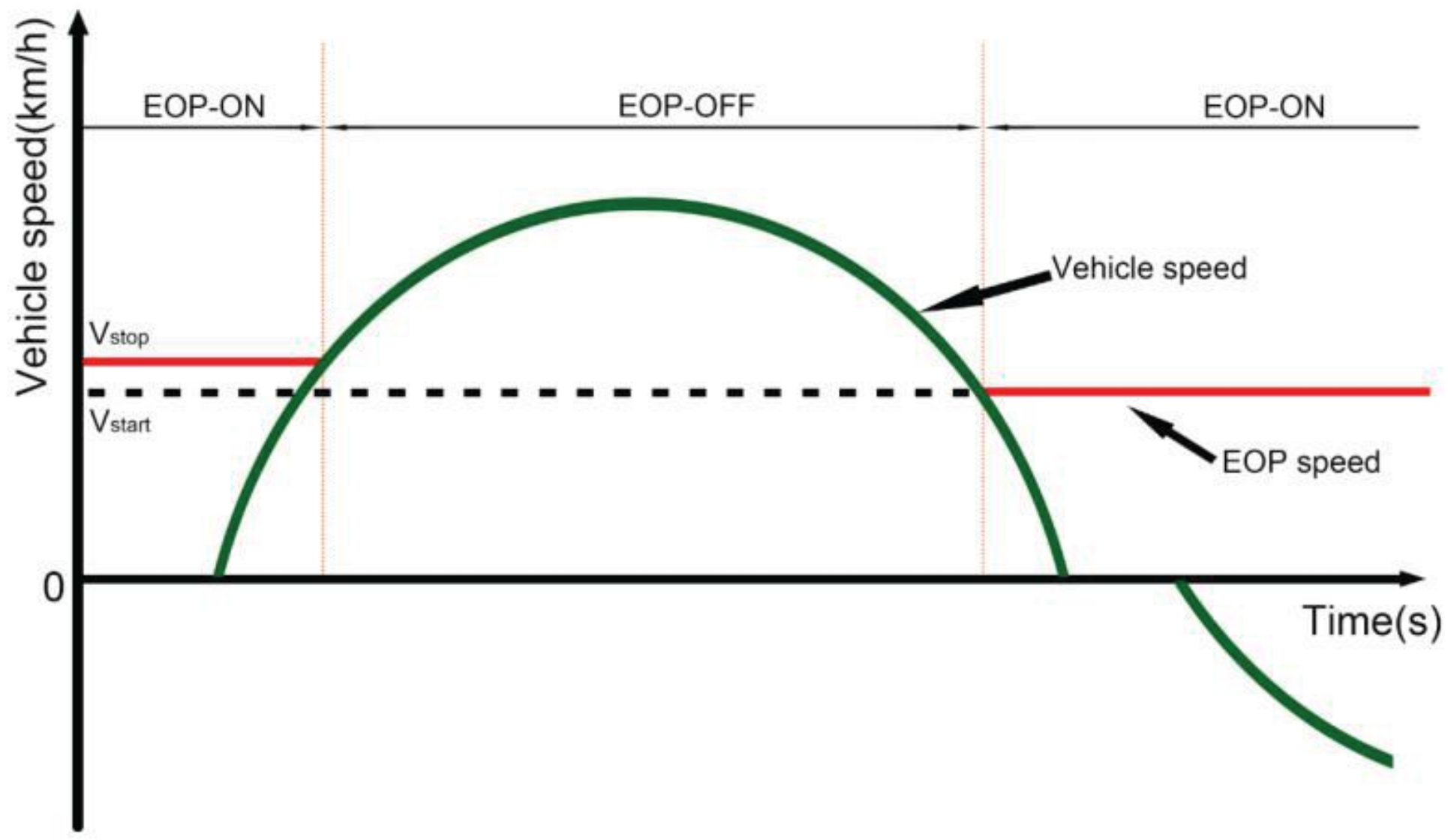

Figure 4

Macro-control strategy for the EOP.

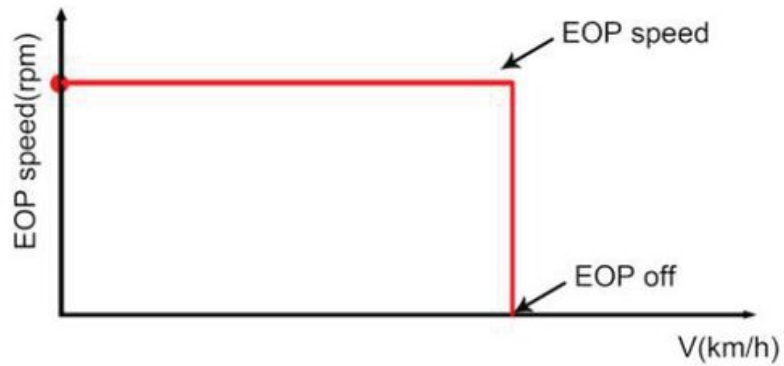

(a) One-speed control

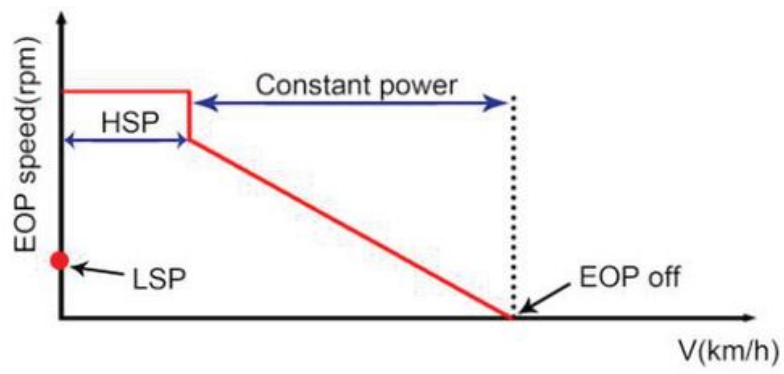

(c) Equal-power control

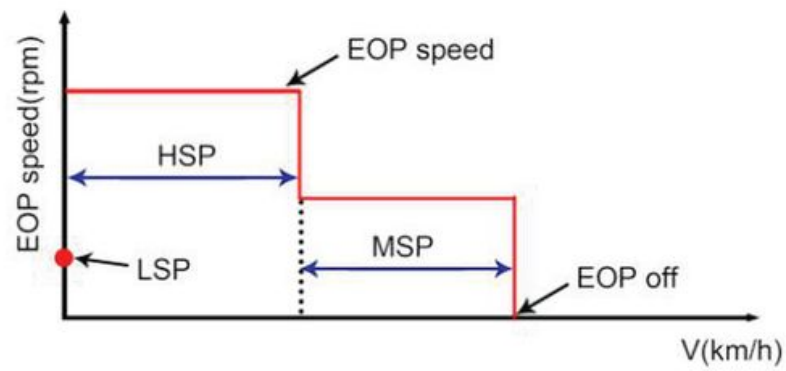

(b) Two-speed control

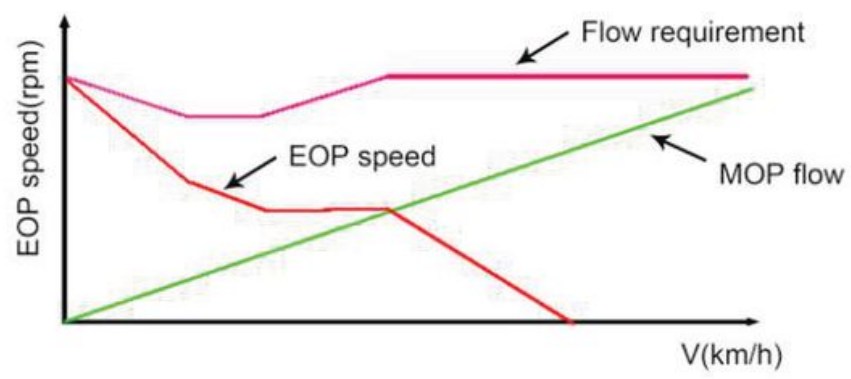

(d) Transient on-demand control 
Figure 5

Four micro-control algorithms for the EOP.

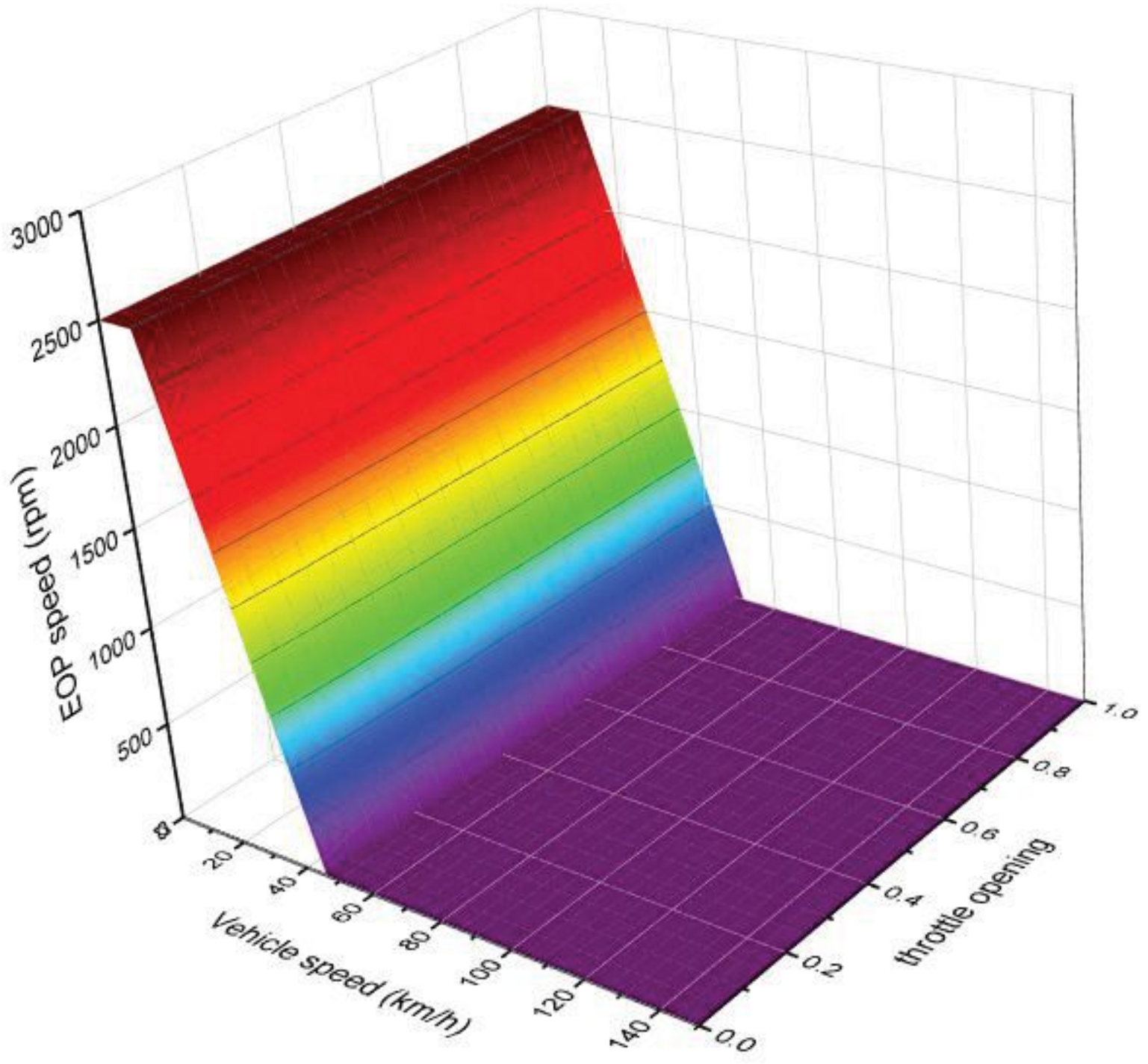

Figure 6

The calculated working map of the EOP.

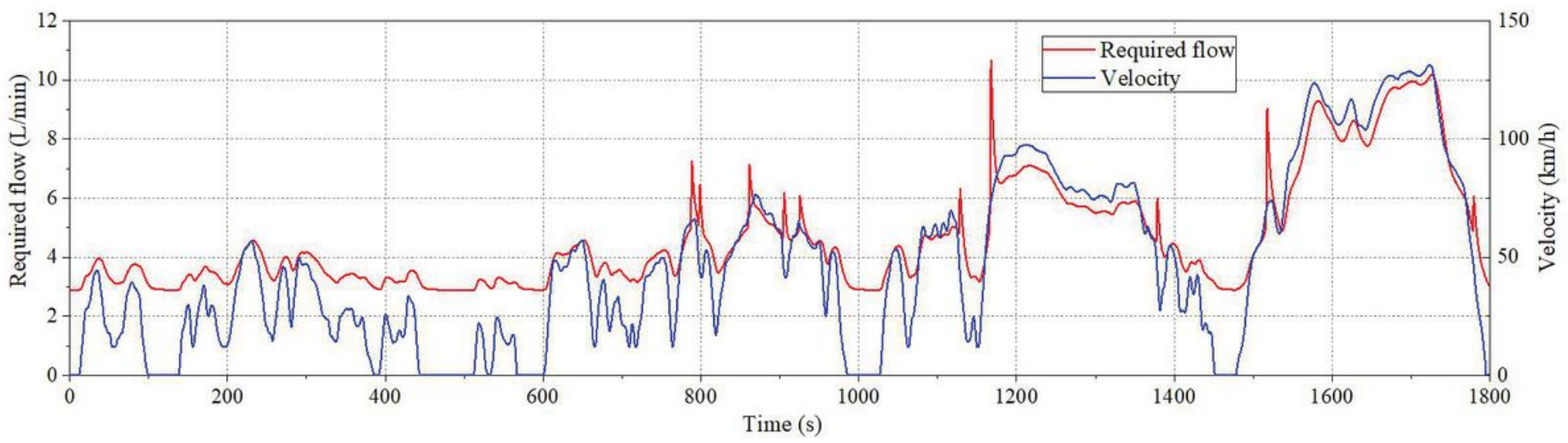


Figure 7

Calculated flow requirement of 2DET in a WLTC driving cycle.

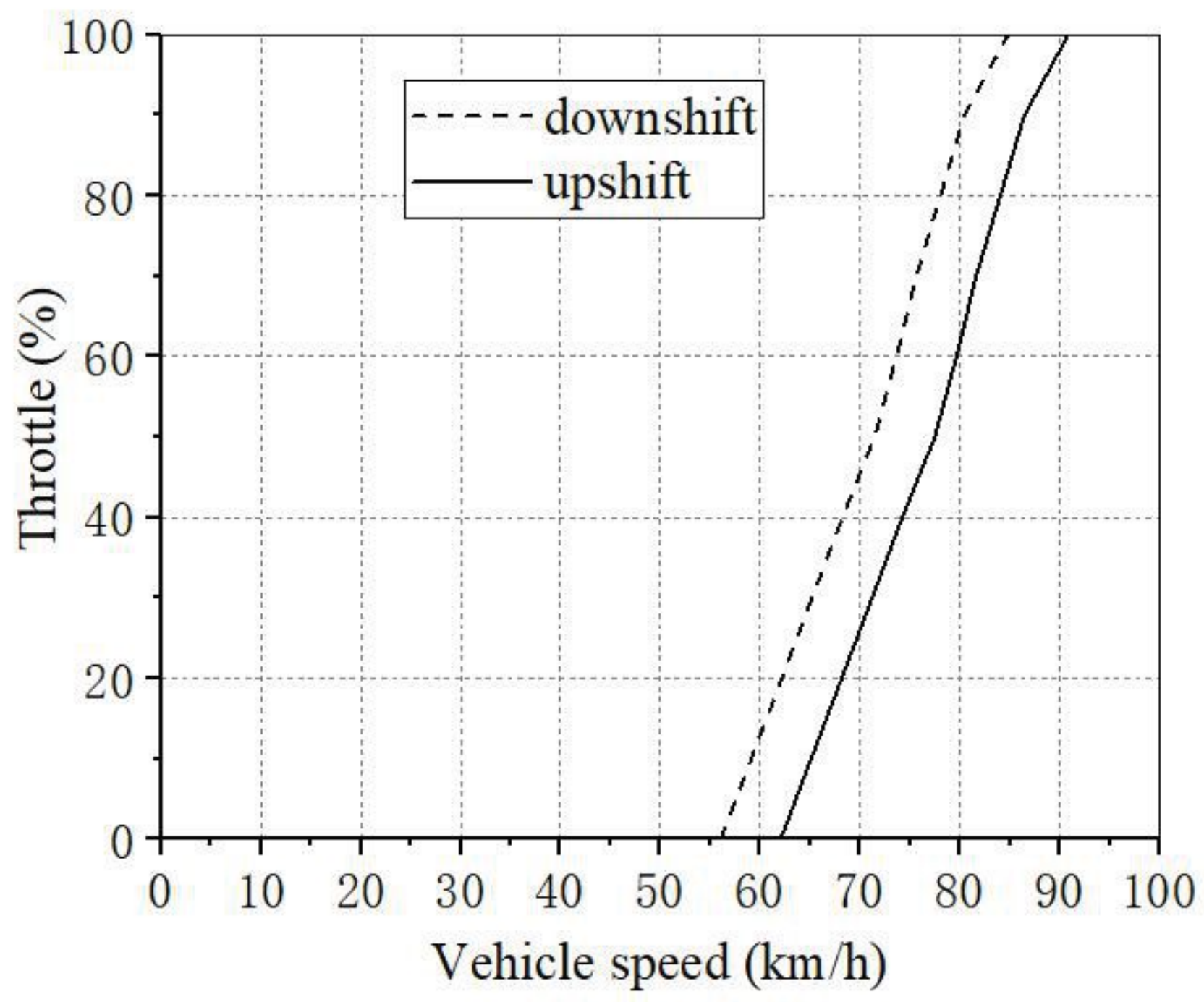

Figure 8

Shift line. 


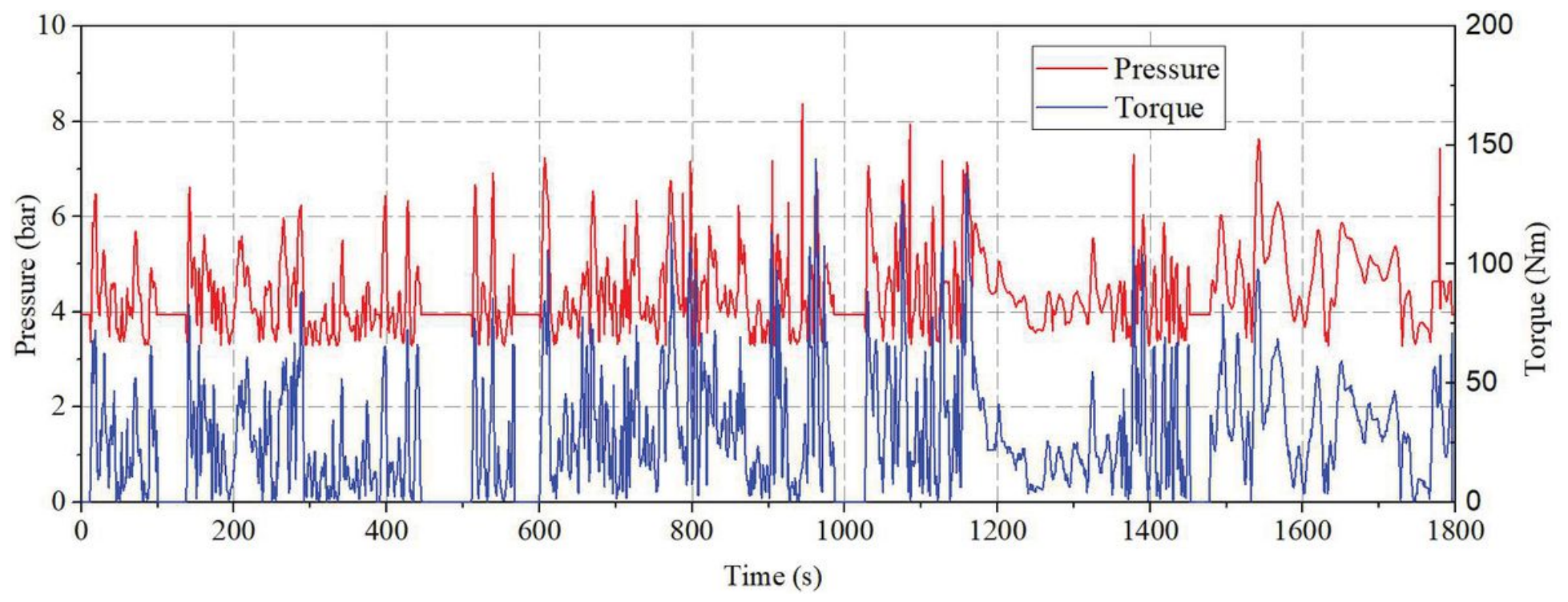

Figure 9

Torque and Clutch pressure demand of 2DET in the WLTC cycle.

Cooling and lubrication system

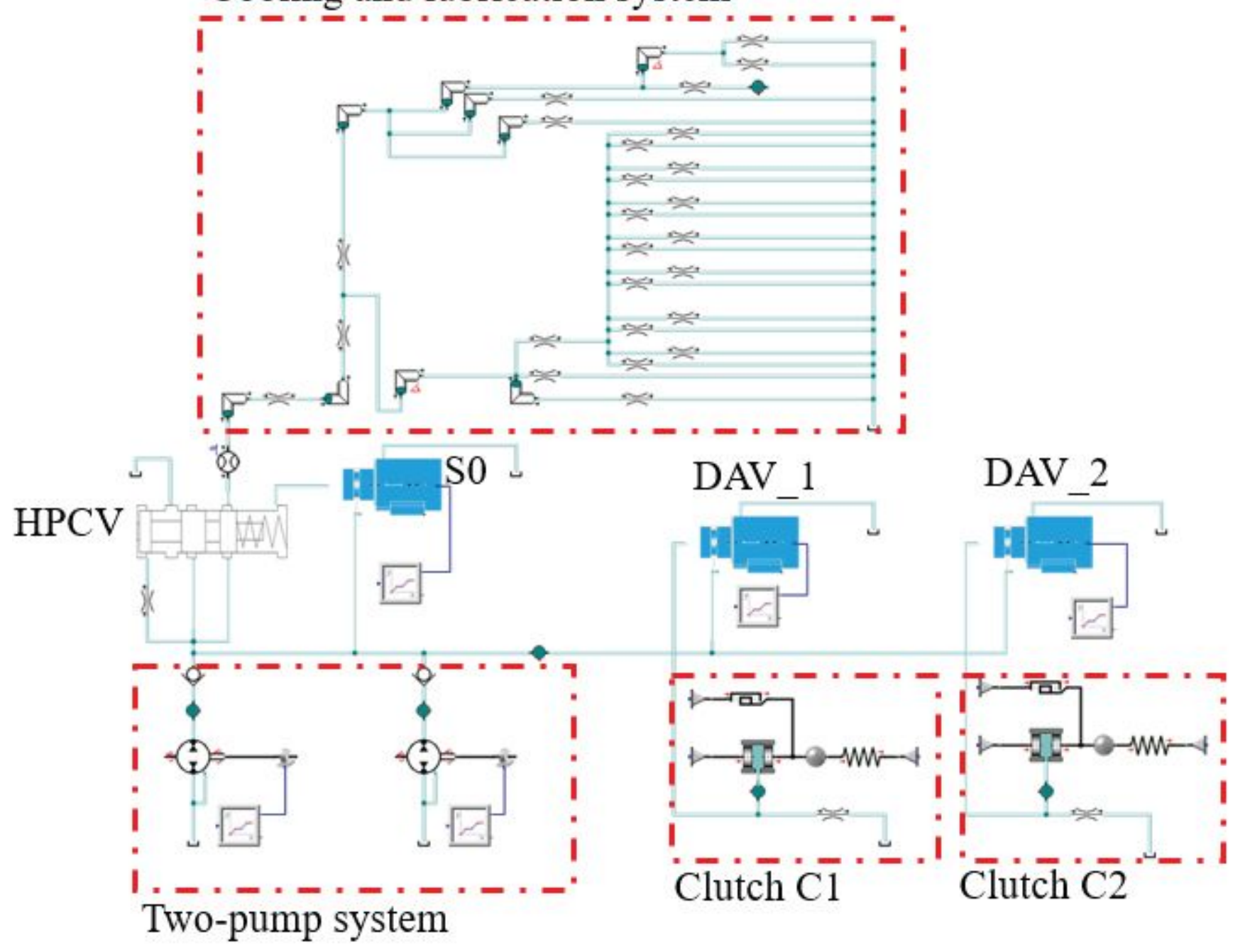


Figure 10

Simulation model for the new-designed two-pump HCU for 2DET.

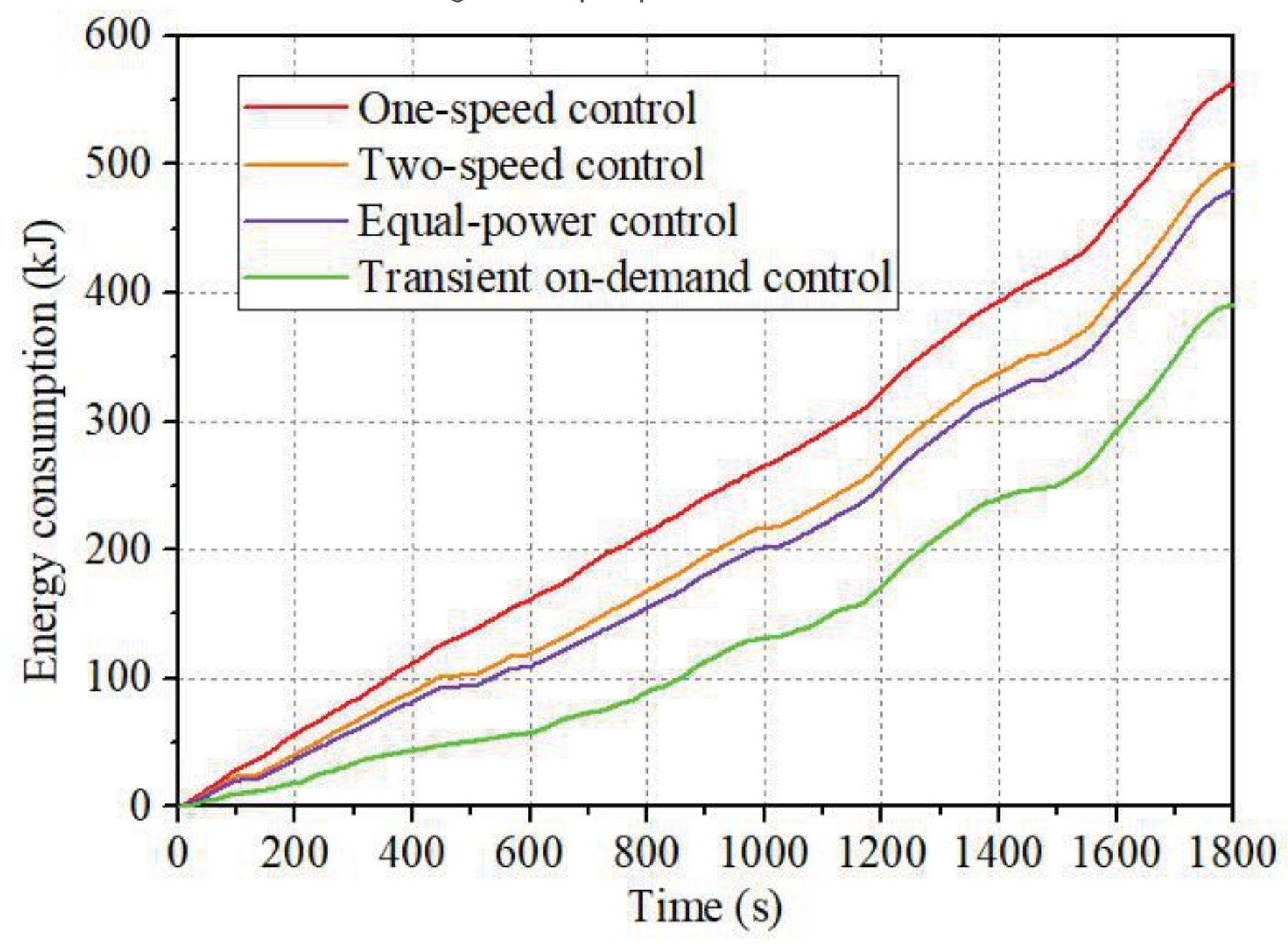

Figure 11

Simulated pump energy consumptions. 


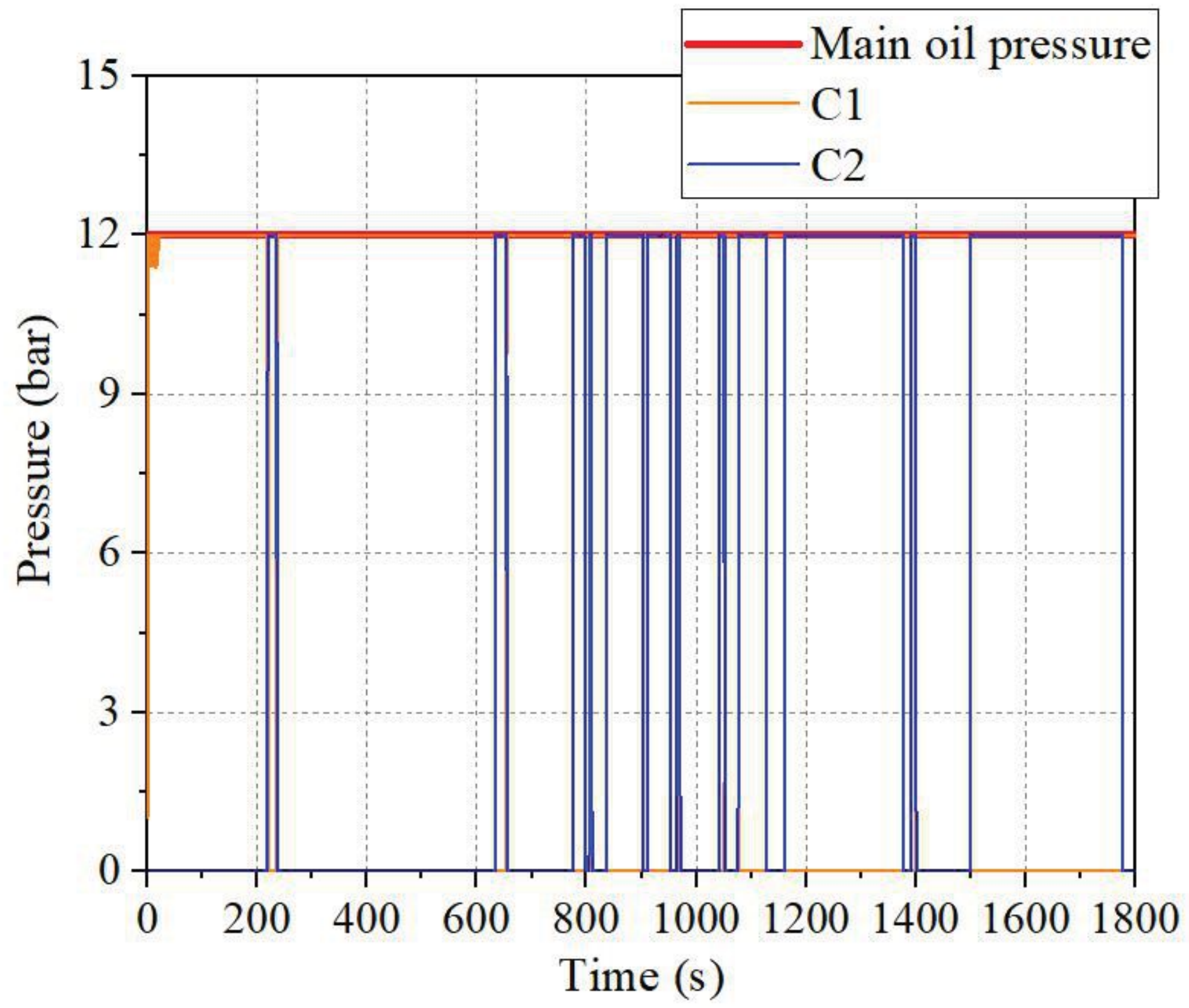

Figure 12

Simulated main line pressure and clutch pressure. 


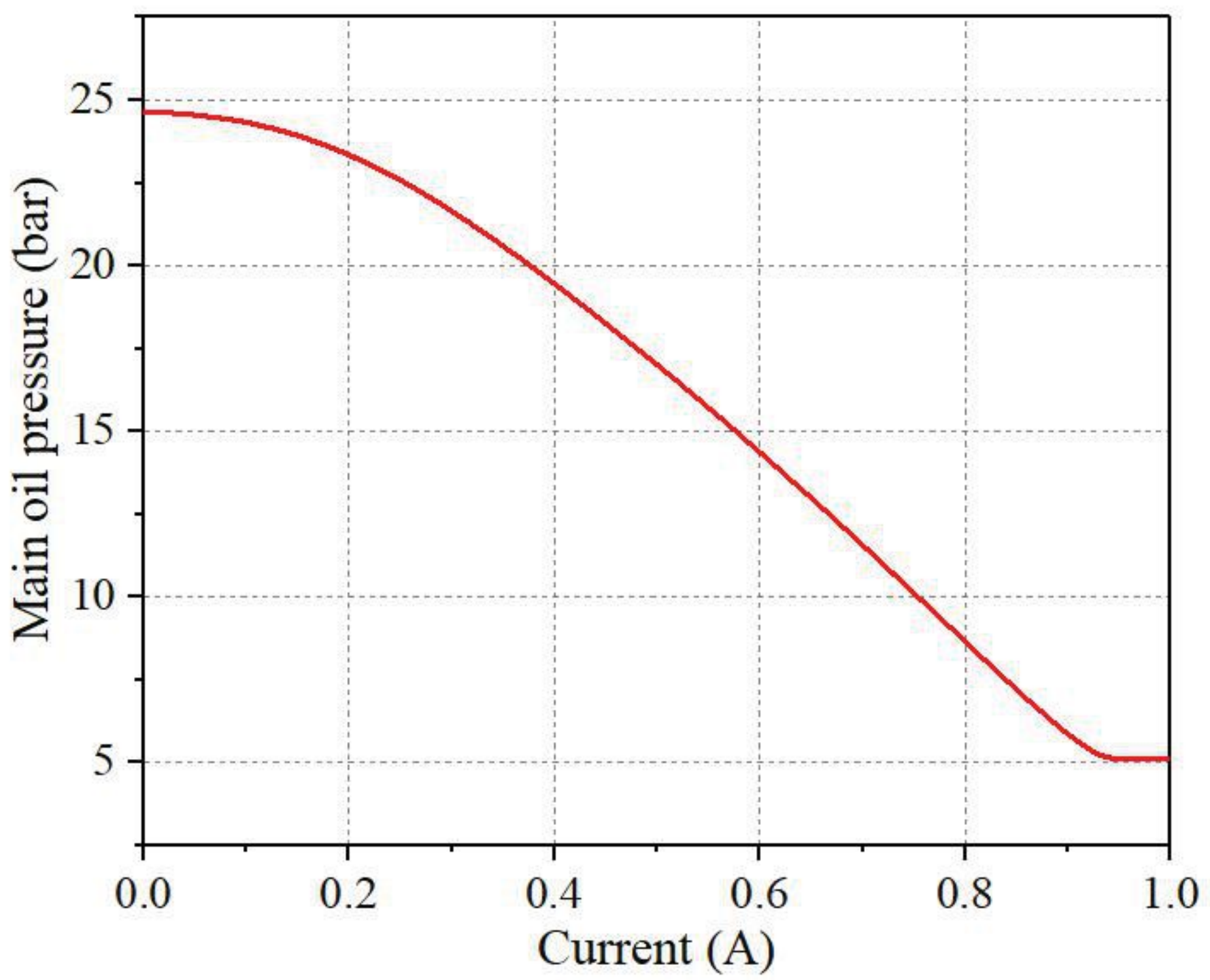

Figure 13

Relationship of main line pressure with current of solenoid valve S0. 


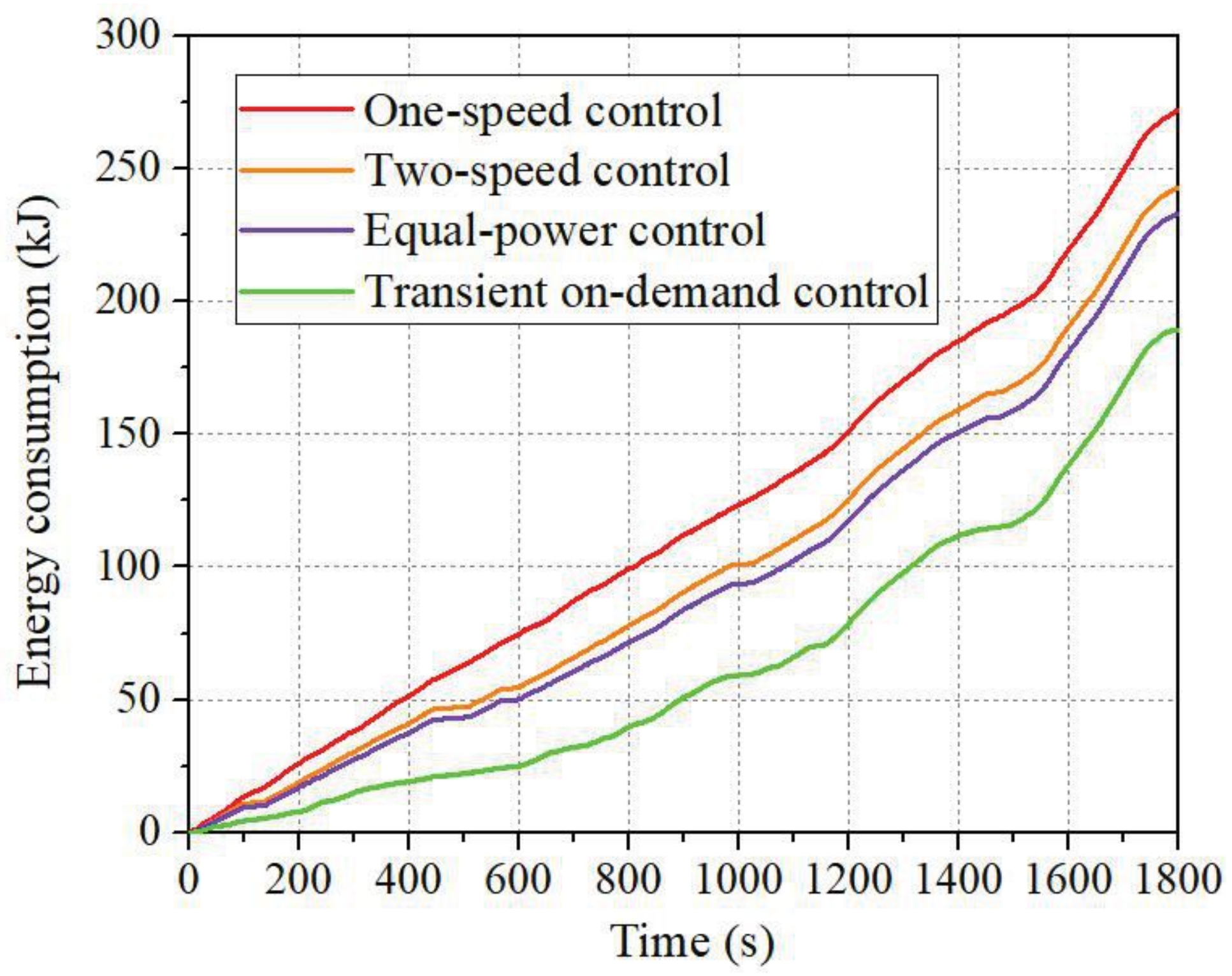

Figure 14

Pump energy consumption with transient main line pressure control. 


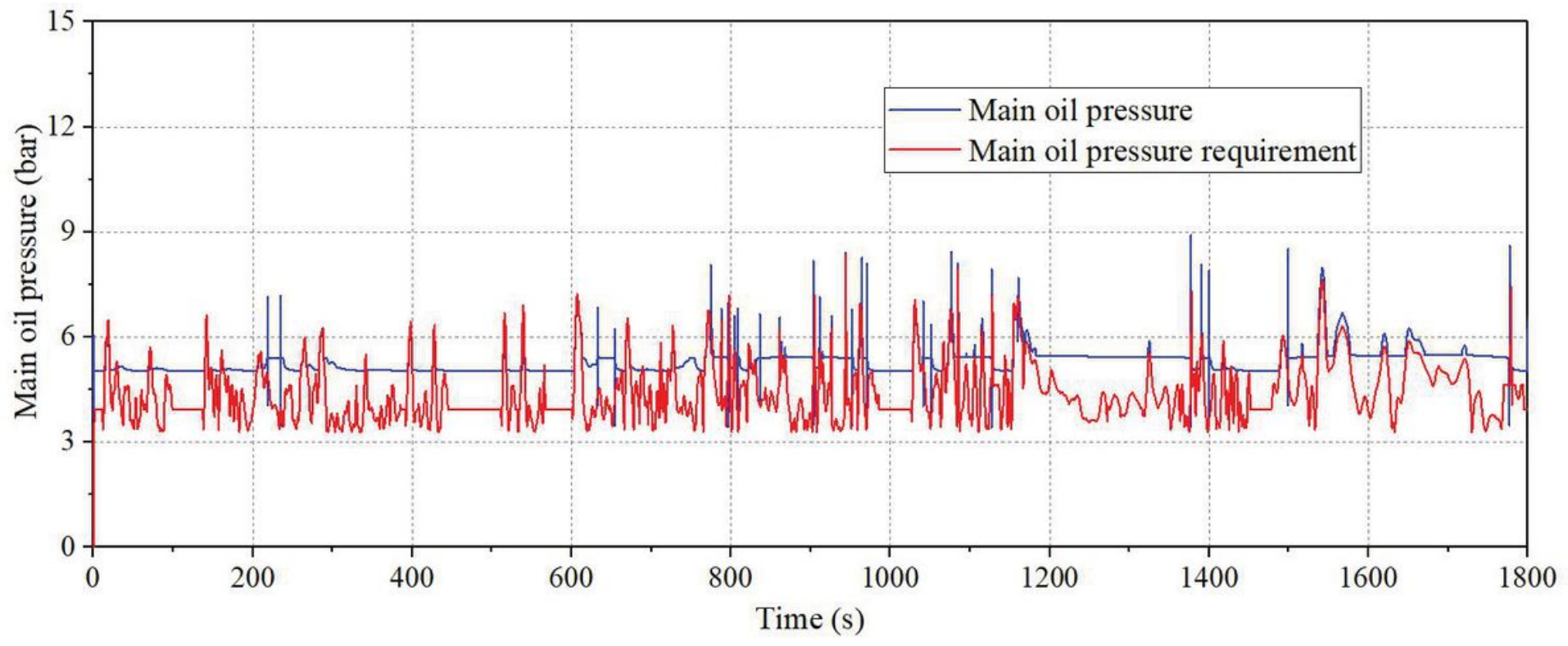

Figure 15

Simulated main line pressure in the driving circle WLTC. 


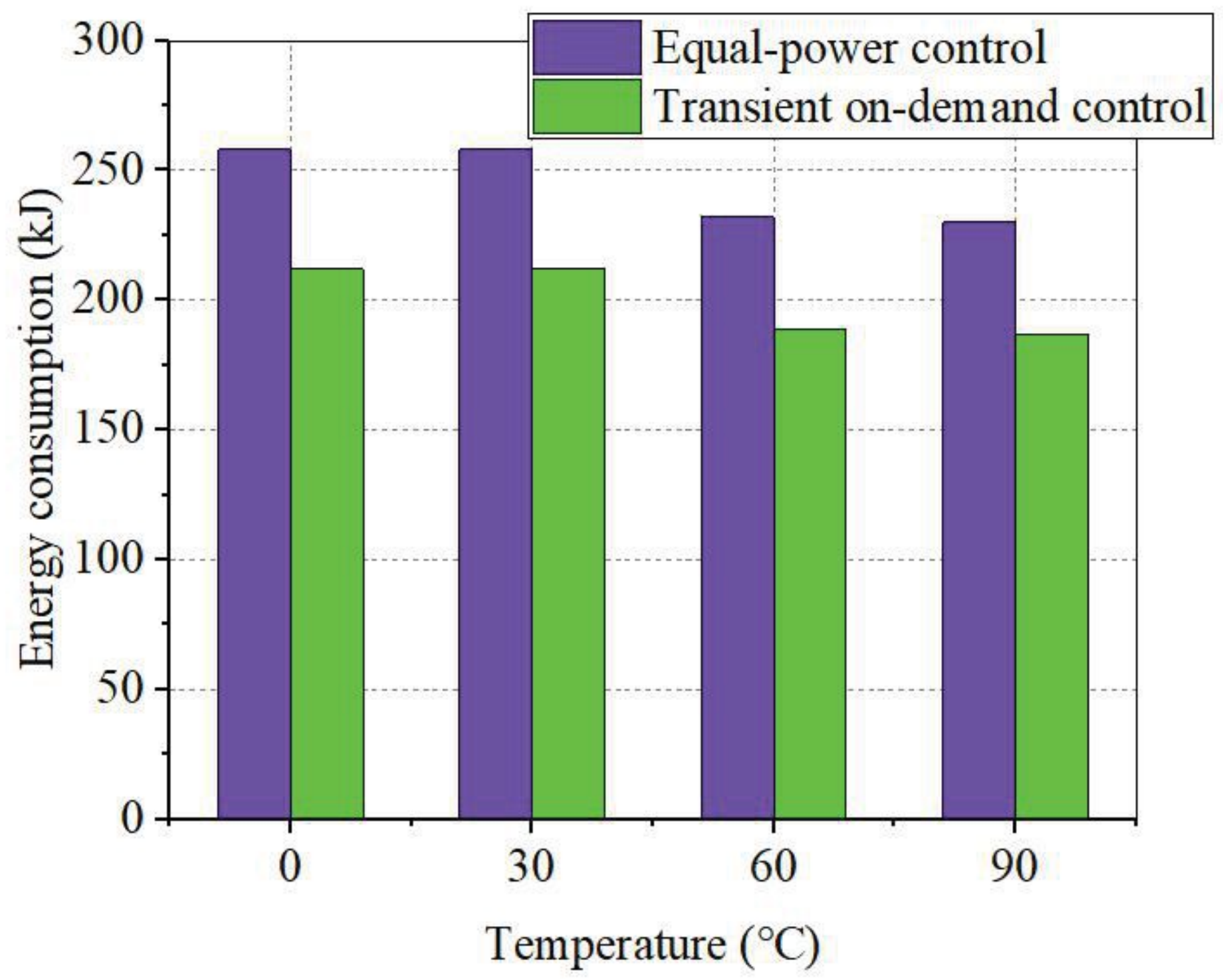

Figure 16

Pump energy consumption under different temperature. 


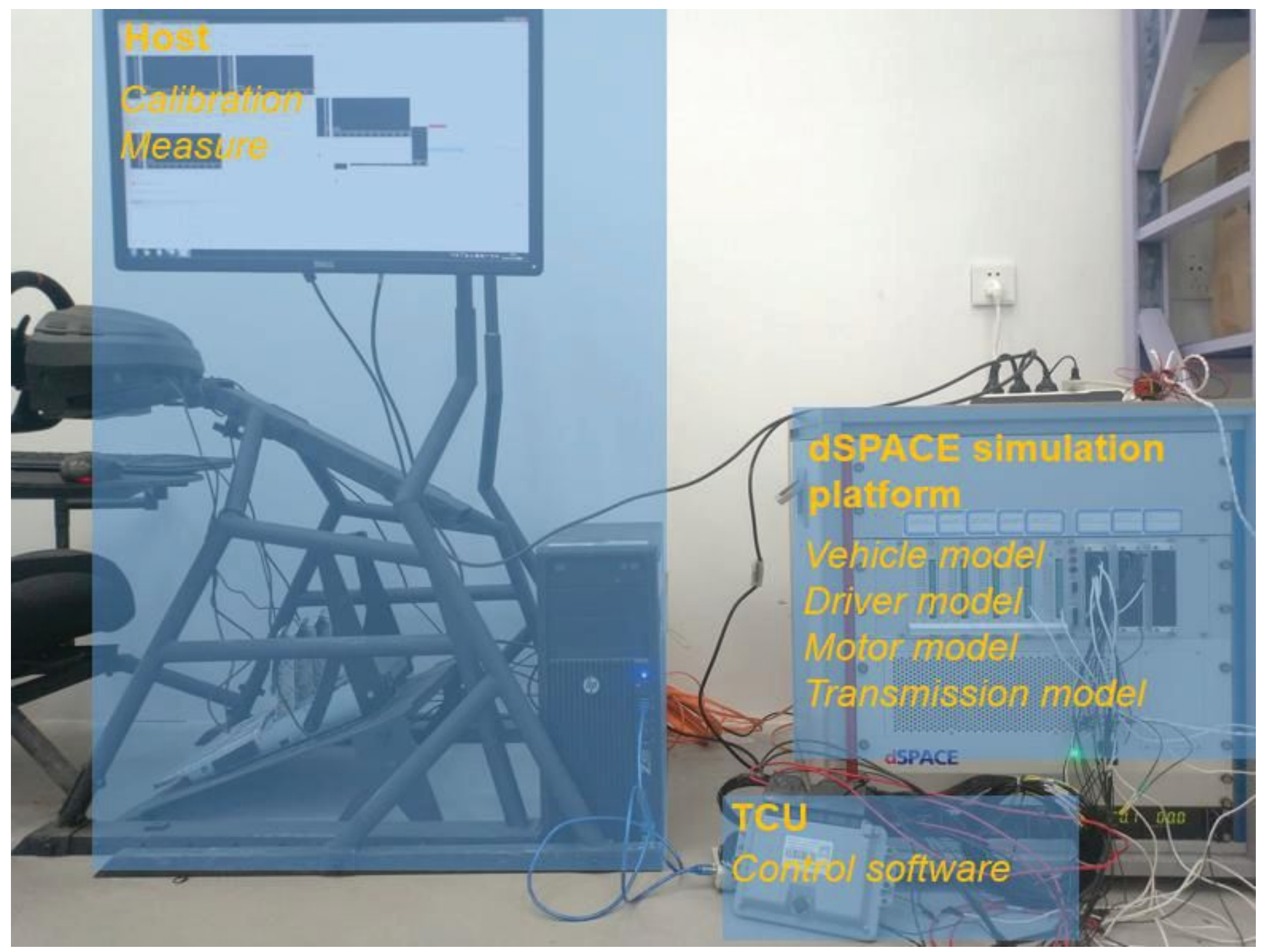

Figure 17

Hardware-in-the-Loop. 


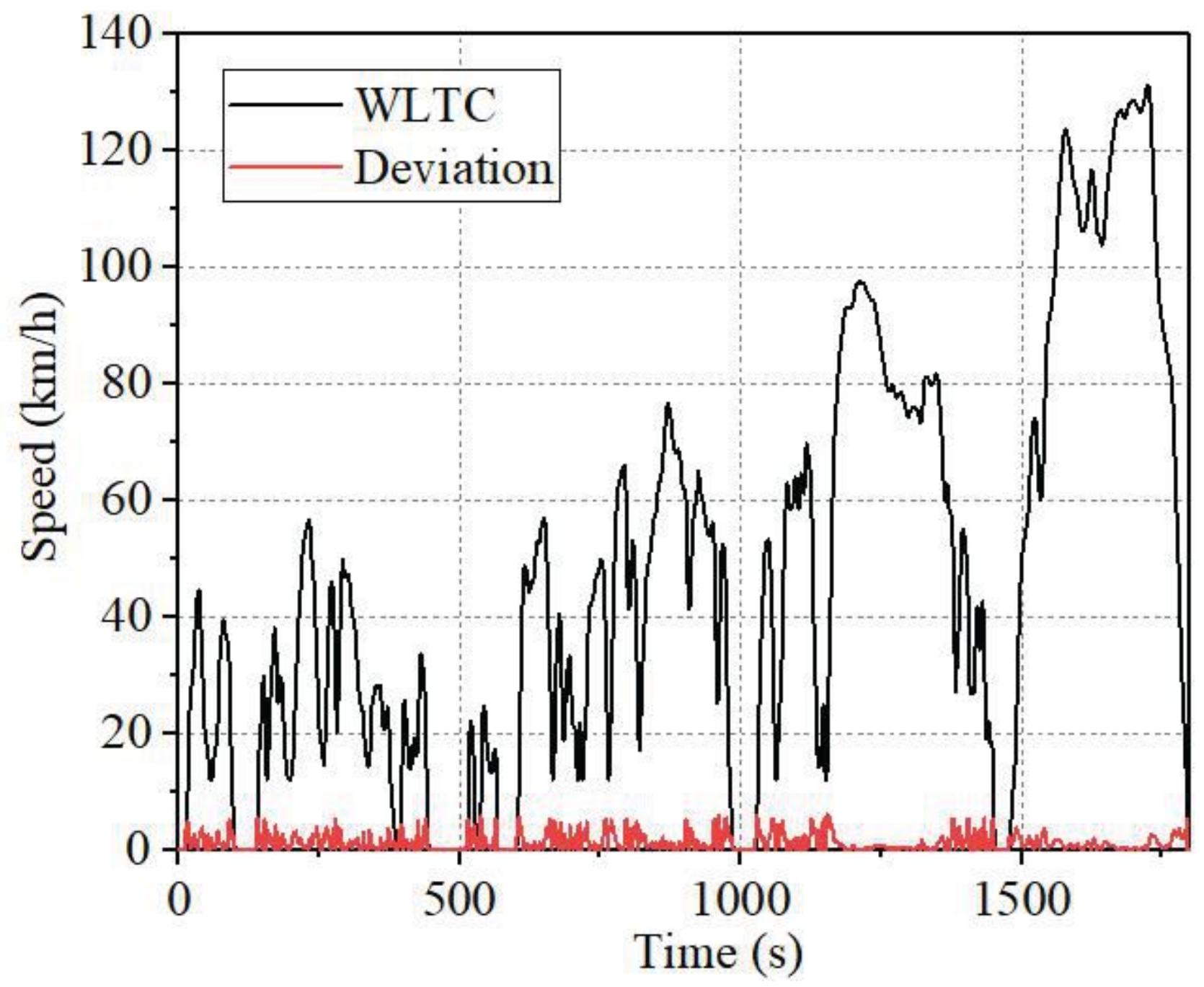

Figure 18

WLTC driving cycle and simulation speed. 


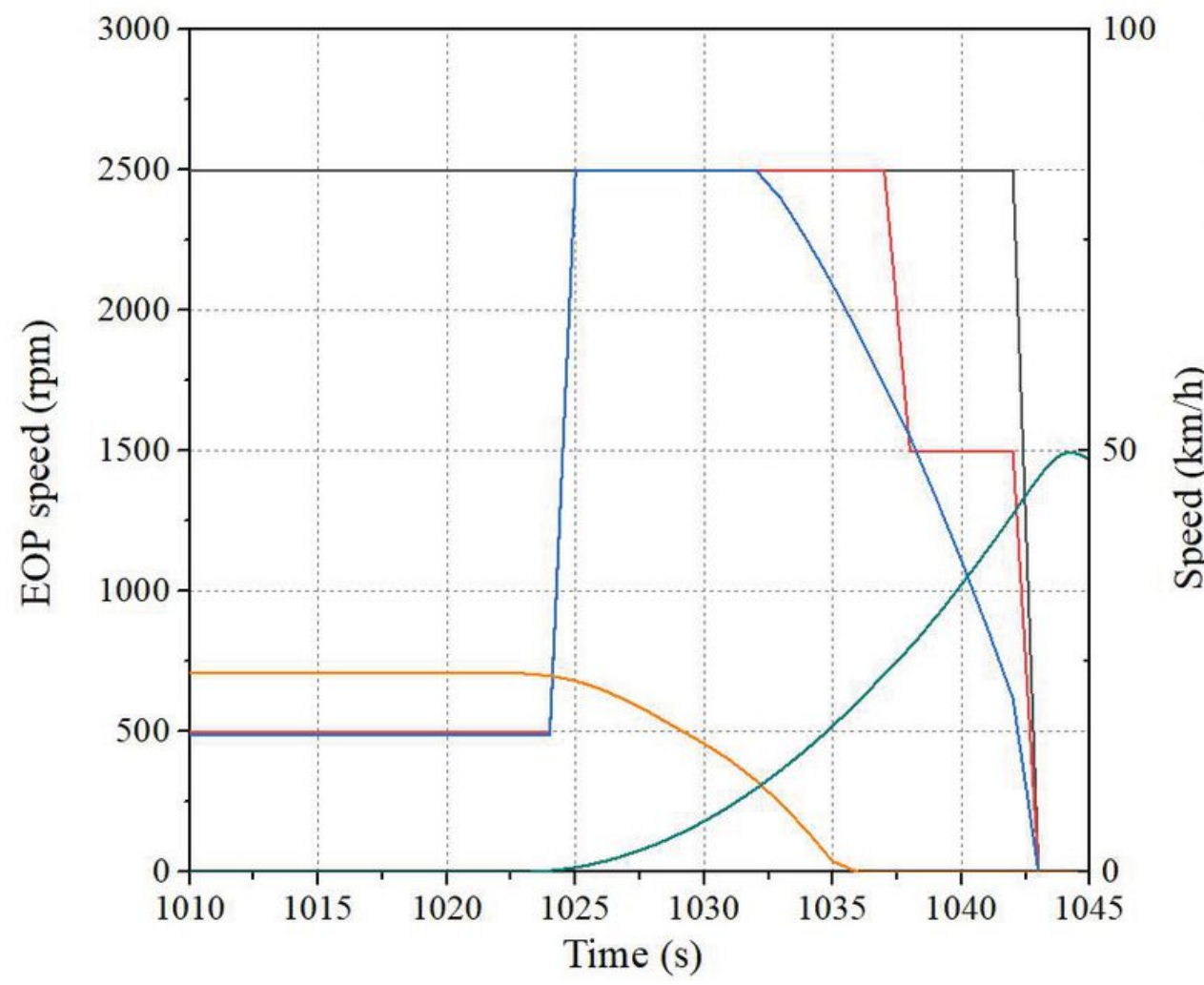

- One-speed control

— Two-speed control

Equal-power control

Transient on-demand control

-...- Vehicle speed

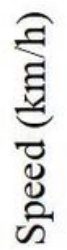

Figure 19

Different control algorithms for the EOP. 


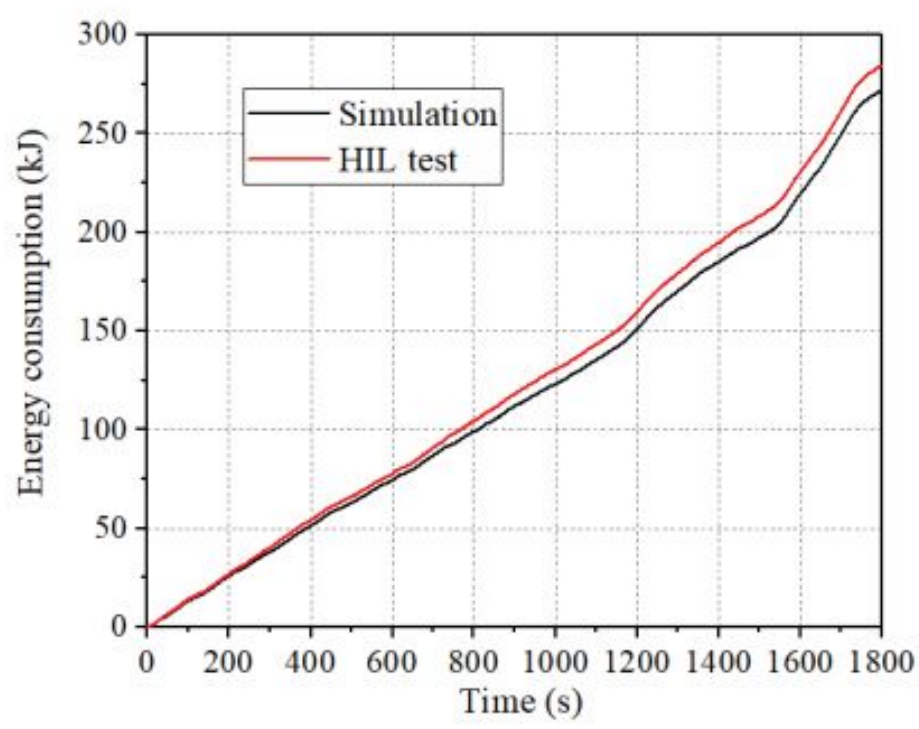

(a)One-speed control

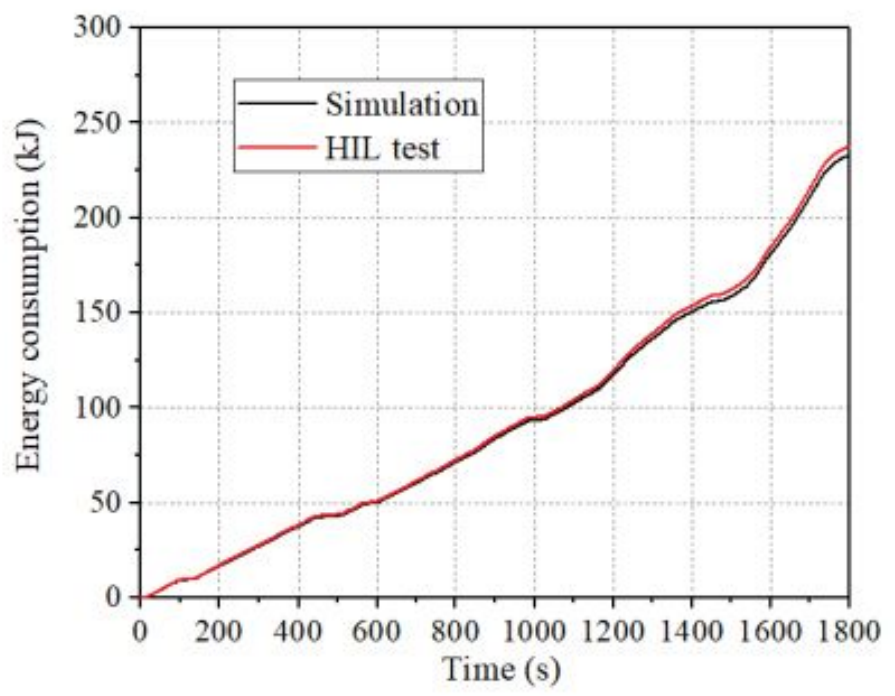

(b) Equal-power control

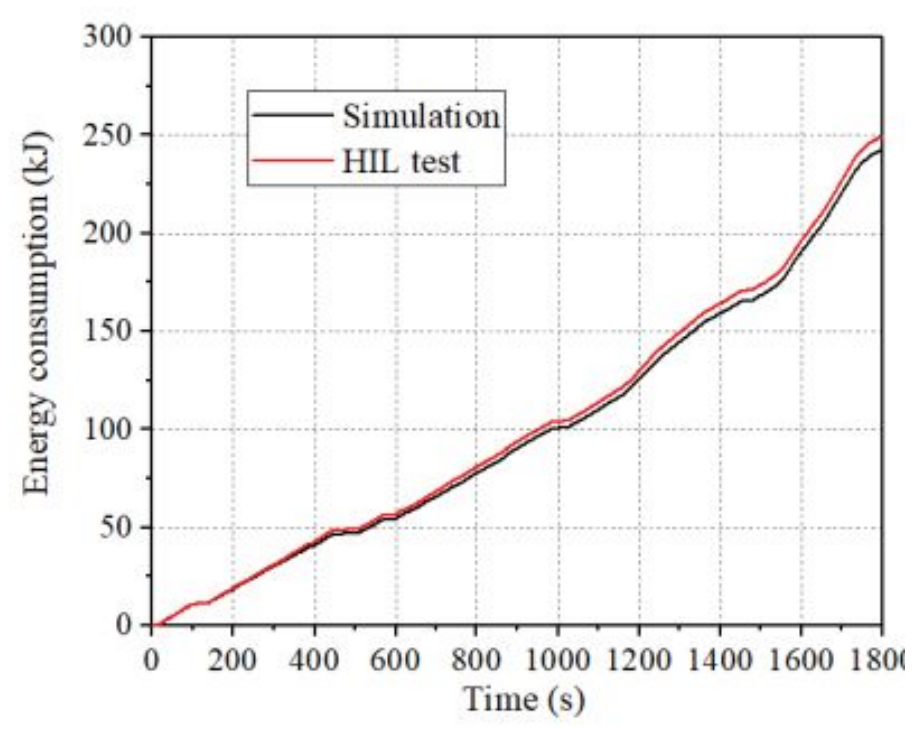

(b)Two-speed control

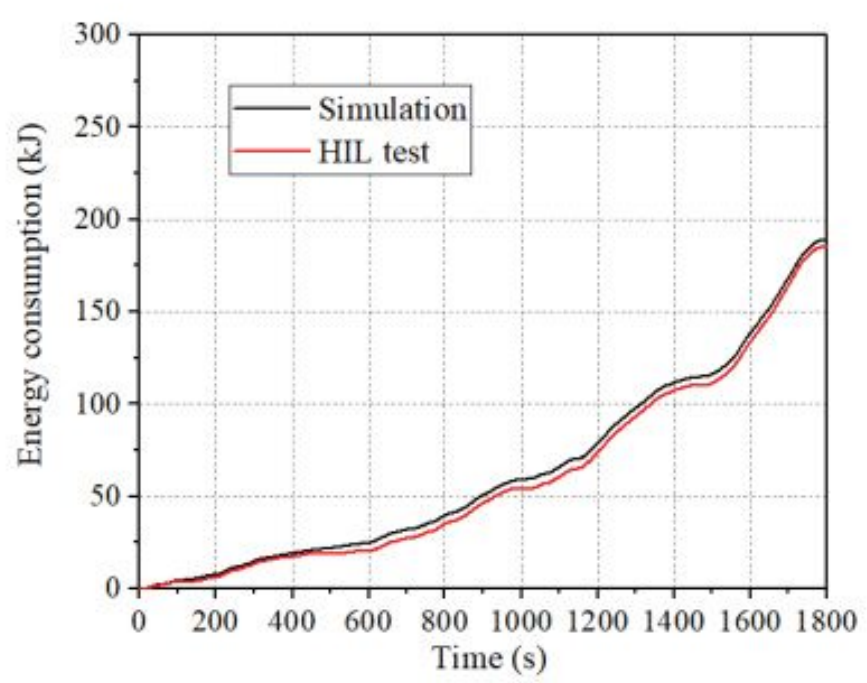

(d)Transient on-demand control

Figure 20

Energy consumption with HIL test results. 